\title{
Cellular and Molecular Mechanisms Regulating Neuronal Growth by Brain-Derived Neurotrophic Factor
}

\author{
Andres Gonzalez,' Guillermo Moya-Alvarado,' Christian González-Billault, ${ }^{2}$ and \\ Francisca C. Bronfman ${ }^{1 *}$ \\ ${ }^{1}$ MINREB and Center for Ageing and Regeneration (CARE UC), Faculty of Biological Sciences, Department of Physiology, Pontificia \\ Universidad Católica de Chile, Santiago, Chile \\ ${ }^{2}$ Laboratory of Cell and Neuronal Dynamics, Department of Biology, Faculty of Sciences, Universidad de Chile and Geroscience Center for \\ Brain Health and Metabolism, Santiago, Chile
}

Received 15 March 2016; Revised 20 May 2016; Accepted 23 May 2016

Monitoring Editor: Peter Baas

\begin{abstract}
Brain-derived neurotrophic factor (BDNF) and its receptors $T r k B$ and $p 75$ regulate dendritic and axonal growth during development and maintenance of the mature nervous system; however, the cellular and molecular mechanisms underlying this process are not fully understood. In recent years, several advances have shed new light on the processes behind the regulation of BDNF-mediated structural plasticity including control of neuronal transcription, local translation of proteins, and regulation of cytoskeleton and membrane dynamics. In this review, we summarize recent advances in the field of BDNF signaling in neurons to induce neuronal growth. () 2016 Wiley Periodicals, Inc.
\end{abstract}

Key Words: BDNF; dendritic growth; signaling; cytoskeleton dynamics; membrane trafficking

\section{Introduction}

$\mathrm{T}$ The functionality of the nervous system (NS) depends on the extent of connectivity achieved by neurons. Although there is wide range of neuronal morphologies, neu-

Abbreviations used: ADF, Actin-depolymerizing factor; ARMS, Ankyrin Repeat-rich Membrane Spanning; BDNF, brain-derived neurotrophic factor; cAMP, cyclic AMP; CNS, central nervous system; GAP, GTPase-activating protein; GEF, guanine nucleotide exchange factor; HD, Hungtington's disease; HTT, huntingtin; JNK, c-Jun amino terminal kinase; MKP1, MAPK phosphatase 1; MVB, multivesicular bodies; NGF, nerve growth factor; NS, nervous system; PLC, phospholipase-C; PNS, peripheral nervous system; PTB, phosphotyrosine binding; PTEN, phosphatase with tensin homolog; RGC, retinal ganglion cells; TNFR, tumor necrosis receptor family.

*Address correspondence to: F. C. Bronfman, MINREB and Center for Ageing and Regeneration (CARE UC), Faculty of Biological Sciences, Department of Physiology, Pontificia Universidad Católica De Chile, Santiago, Chile. E-mail: fbronfman@bio.puc.cl Published online 13 June 2016 in Wiley Online Library (wileyonlinelibrary.com). rons are specialized to form part of a given neuronal circuit and thus their morphology must adjust to this task [Gao, 2007]. In this regard, neurons are highly polarized cells composed of two main domains: the somato-dendritic compartment where neurons receive and integrate information from several axonal inputs and axons that are responsible for transmitting the action potential and conveying the information to the next relay in the network. A close relationship between the appropriate development of dendrites and axons and the functionality of the NS has been described. For example, alterations in dendrites, axonal inputs and dendritic spines are linked to neurodevelopmental and neuropathological conditions. Thus, the study of the mechanisms implicated in the regulation of neuronal morphology during development and maintenance of the adult NS is a focus of intense research [Armstrong et al., 1998; Wood et al., 2004; Bronfman et al., 2007; Dickstein et al., 2010; Cabeza et al., 2012; Eiland and McEwen, 2012; Kulkarni and Firestein, 2012].

Neuronal morphology is regulated by both intrinsic and extrinsic factors, whose actions are overlapping. The intrinsic factors are described as the action of the genetic program of neurons that leads to a basic pattern of branching. In addition to this, there is an extensive list of molecules grouped as extrinsic factors that shape axonal and dendritic morphology throughout development and in response to sensory experience. These include bone morphogenetic family proteins (BMPs), semaphorins, Reelin, neurotrophins, and neuronal activity, among others [Jan and Jan, 2010]. The mechanisms underlying the effects of external cues to induce dendritic and axonal branching have only begun to be understood, and several steps including stimulation of intracellular signaling pathways to activate specific transcription factors, local synthesis of proteins and cellular membrane addition and turnover are involved. An interesting point of convergence is the effect of these external signals on the stability and dynamics of the cytoskeleton and the activity of molecular motors [Horton and Ehlers, 2004; 
Flavell and Greenberg, 2008; Jan and Jan, 2010]. Among the external cues that regulate neuronal morphology are neurotrophins. In recent years, several investigations have shed new light on the mechanisms used by neurotrophins to induce morphological changes [Park and Poo, 2013]. In this review, we will summarize some specific studies showing evidence that increases our understanding of the mechanisms underlying BDNF-induced dendritic and axonal branching with a focus on neurons of the central nervous system (CNS).

\section{Neurotrophin Receptors and Signaling}

Neurotrophins were first described as target-derived growth factors that regulate the survival, axonal growth and differentiation of neurons in the peripheral nervous system (PNS) [Levi-Montalcini, 1987; Huang and Reichardt, 2001]. It was later shown that neurotrophins have multiple functions in the CNS including regulation of neuronal morphology and plasticity. Over the last few years, it has been shown that neurotrophins can be secreted from different types of cells including neurons to stimulate paracrine and autocrine actions [Bronfman et al., 2014, and references therein].

Neurotrophins are a small family of soluble factors that include nerve growth factor (NGF), brain-derived neurotrophic factor (BDNF) and neurotrophin 3 and 4 (NT3 and NT4). There are two types of neurotrophin receptors, the tropomyosin-related kinase receptors (Trks) and the p75 neurotrophin receptor (p75) [Kaplan and Miller, 2000]. The Trks are relatively specific: TrkA binds NGF as well as NT3, although with less affinity; TrkB binds BDNF as well as NT4, although with less affinity; and TrkC binds NT3. On the other hand, p75 binds all neurotrophins with similar affinity, in addition to other ligands such as proneurotrophins (see below) [Huang and Reichardt, 2003].

Neurotrophins are homodimeric proteins that are synthesized as precursors (proneurotrophins) and secreted to the extracellular space as mature proteins in both a constitutive and regulated manner. For many years, the pro-domain of neurotrophins was considered to only play a role in the secretion and folding of the neurotrophins in the secretory pathway. However, the Hempstead group reported that there are also significant levels of proneurotrophins in tissue and cell culture supernatants, and the physiological roles of the proneurotrophins -by binding a complex of membrane receptors that include p75-in healthy and injured neurons have started to emerge [Park and Poo, 2013; Hempstead, 2014].

The cellular effects regulated by neurotrophin-mediated activation of Trk receptors include proliferation and survival; axonal and dendritic growth; assembly and remodeling of the cytoskeleton; membrane trafficking and fusion; and synapse formation, function, and plasticity [Huang and
Reichardt, 2001; Park and Poo, 2013; Deinhardt and Chao, 2014b]. Upon ligand binding, the Trk receptors dimerize and undergo autophosphorylation in specific tyrosines of the intracellular domain. These phosphotyrosines are potential docking sites for proteins containing phosphotyrosine binding (PTB) and Src homology 2 (SH2) binding domains and lead to the activation of several signaling cascades that include the mitogen-activated protein kinases (MAPKs), such as ERK1/2, ERK5 and p38, in addition to phosphatidylinositol-3-kinase (PI3K)-Akt, phospholipase-C (PLC) $-\gamma-\mathrm{Ca}^{2+}$ and the small GTPases of the Rho family Cdc42/Rac/RhoA [Huang and Reichardt, 2003; Minichiello, 2009] (see Fig. 1A).

The p75 neurotrophin receptor is a member of the tumor necrosis receptor family (TNFR) and does not possess an intracellular catalytic domain; therefore, it signals through interaction with intracellular signaling adaptors that link ligand binding to the activation of specific signal transduction pathways. The signaling pathways activated by p75 result in the production of ceramides, the nuclear translocation of NFKB, the phosphorylation of the c-Jun amino terminal kinase (JNK), and the regulation of RhoA activity [Kraemer et al., 2014]. p75 can form different signaling complexes based on its interaction with different coreceptors in the membrane and different ligands, such as proneurotrophins. This result in opposing biological action upon p75 activation including survival or induction of cell death and extension or inhibition of neuronal process growth [Kraemer et al., 2014].

\section{Evidence Indicating that BDNF and its Receptors are Major Regulators of Neuronal Morphology in the CNS}

BDNF and its receptor TrkB represent the most widely expressed and studied neurotrophin signaling pathway in the brain, and its participation in learning and memory is well established [Minichiello, 2009; Park and Poo, 2013]. The finding that BDNF is synthesized and secreted in an activity-dependent manner inspired more than two decades of study on the role of neurotrophins in activity-dependent plasticity and strengthening of synaptic function. Indeed, there is good evidence that BDNF can be secreted from axons and dendrites in an activity-dependent manner. Dense core vesicle-like structures have been observed in axons, while vesicles without dense cores are found in dendrites [Park and Poo, 2013; Edelmann et al., 2014]. Indeed, distinct subsets of BDNF-positive vesicles are sorted to axons and dendrites [Dean et al., 2012]. Both types of vesicles share a similar fusion machinery; however, they are different from the neurotransmitter synaptic vesicles and do not necessarily fuse at the active sites of the preformed synapses [Shimojo et al., 2015]. Therefore, neuronal activity results in increased BDNF release in the pre- and post- 
synaptic compartments of neurons where it can regulate structural plasticity, including dendritic and axonal growth. This is discussed below.

In the CNS, cortical neurons express $\operatorname{TrkB}$ and $\operatorname{TrkC}$ and low levels of $\mathrm{p} 75$, and there is good evidence that BDNF and NT3 increase dendritic and axonal branching by activating TrkB and TrkC [Horch and Katz, 2002; Cheung et al., 2007; Guillemard et al., 2010; Lazo et al., 2013]. There is little information on the role of p75 in CNS neuronal morphology; however, there is one report indicating that the expression of $\mathrm{p} 75$ reduces the number of secondary dendrites of adult hippocampal neurons, suggesting that p75 has an opposing role to that of the Trks, as reported for the PNS [Glebova and Ginty, 2005; Zagrebelsky et al., 2005]. Supporting this idea, recent results show that, by binding to $\mathrm{p} 75$, proBDNF (the non-processed form of BDNF) negatively regulates neuronal remodeling, synaptic transmission and synaptic plasticity in hippocampal neurons [Yang et al., 2014]. These results are in agreement with the reported effect of proBDNF and p75 in long-term
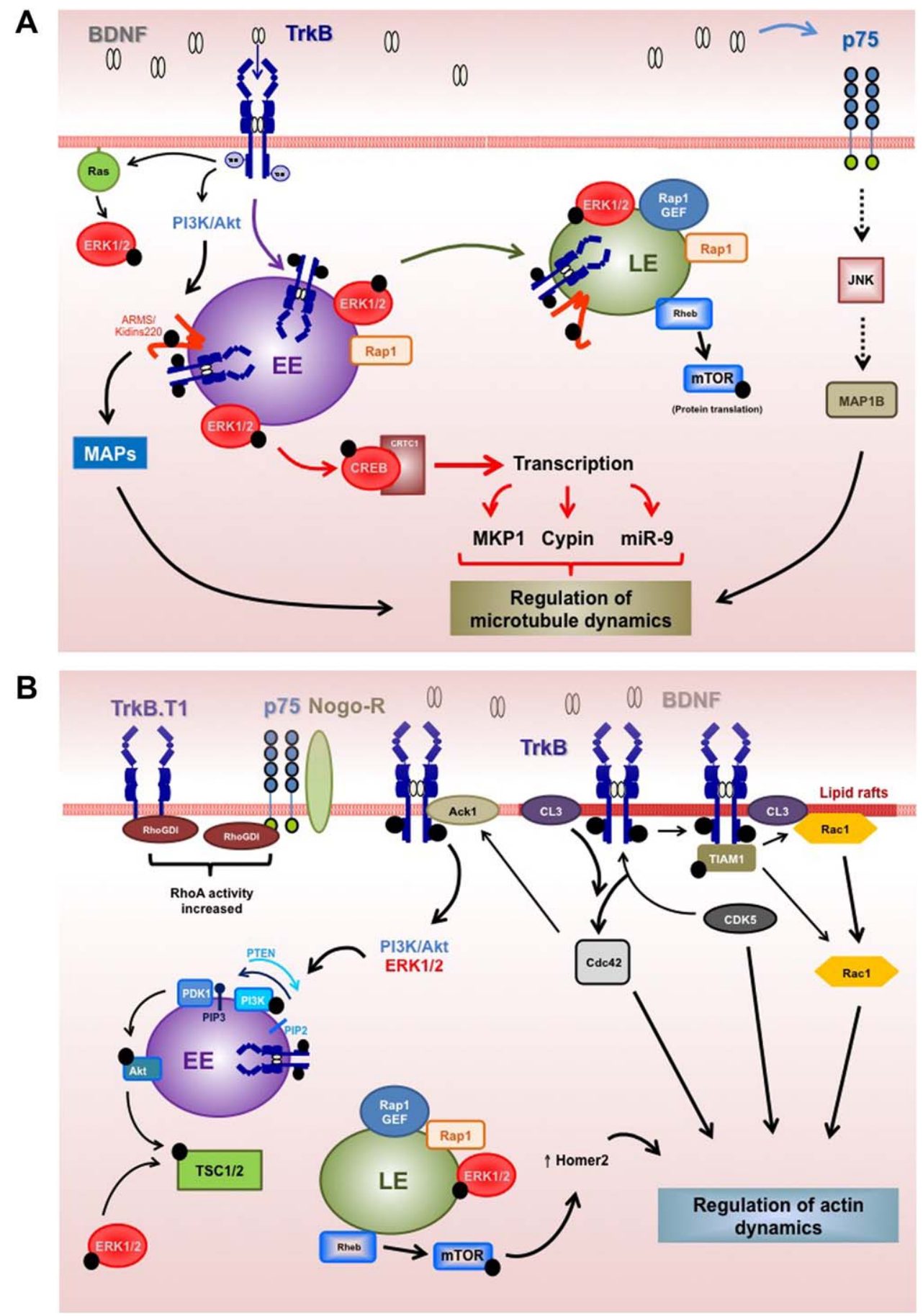

Fig. 1. 
depression [Park and Poo, 2013]. On the other hand, there are a few reports indicating that neurotrophin binding to p75 increases neurite outgrowth and is required for the induction of axon specification during CNS development. Interestingly, cortical pyramidal neurons from layer $2 / 3$ require p 75 for axon formation during development [Higuchi et al., 2003; Zuccaro et al., 2014]. Indeed, it has been shown that, during axon-dendrite polarization, secretion of BDNF at the growth cone could serve as an autocrine factor for axon initiation and growth via a positive feedback loop involving BDNF-induced BDNF release and local insertion of TrkB into the membrane through a cyclic AMP (cAMP)/ PKA-dependent mechanism, thereby modulating neuronal morphology [Cheng et al., 2011]. Work by Zuccaro and collaborators has shown that this BDNF effect requires p75 [Zuccaro et al., 2014].

TrkB is the most widely expressed Trk in the CNS [Yan et al., 1997] and conditional deletion of TrkB in the adult CNS induces dendritic retraction and neurodegeneration of cortical neurons [Xu et al., 2000]. In addition, BDNF mRNA and protein and its receptors TrkB and p75 are found in the neocortex in the CNS [Edelmann et al., 2014, and the references therein]. Conditional deletion of BDNF from the neocortex in embryogenesis using CRE-mediated recombination demonstrated that cortical layer $2 / 3$ neurons developed normally with normal size and dendrites, but they later shrank in size and exhibited a reduction of dendritic complexity at 3 weeks of age, when BDNF expression normally rises dramatically in the cortex, suggesting that BDNF expression is required for the maintenance of dendritic structures and not for the initial survival of these neurons [Gorski et al.,2003]. New evidence suggests that axonal BDNF regulates terminal axonal branching in layers $2 / 3$ and 5 in the cortico-callosal pathway (formed by projecting axons of cortical layer $2 / 3$ neurons) in an autocrine manner [Shimojo et al., 2015]. In addition, cortical neurons anterogradely transport BDNF to the striatum through the cortico-striatal pathway. Mice lacking cortical BDNF showed a reduction of dendritic complexity followed by a loss of striatal neurons as well as a hindlimb clasping phenotype, which was similar to huntingtin (HTT) mutant mice [Baquet et al., 2004; Bruns and Miller, 2007; Rauskolb et al., 2010]. Consistently, mutant HTT impairs BDNF axonal transport, suggesting that impaired $\mathrm{BDNF} / \operatorname{TrkB}$ signaling underlies the neurological phenotype in Hungtington's disease (HD) [Gauthier et al., 2004; Roze et al., 2008]. Together, these results suggest that BDNF release from cortical axons regulates the dendritic and axonal arborization of different neurons in a connected circuit in an autocrine and paracrine manner. Indeed, the growth-promoting effect of $\mathrm{BDNF} / \mathrm{TrkB}$ has also been described for inhibitory GABAergic interneurons in the cortex [Park and Poo, 2013] and for proper growth of dendrites from Purkinje neurons [Schwartz et al., 1997].

The TrkB receptor is found in two main forms: the 145 $\mathrm{kDa}$ full-length version (also referred to as TrkB-FL) and an

Fig. 1. Signaling pathways involved in BDNF-induced dendritic and neuronal growth. (A) BDNF binds its membrane receptors TrkB and p75 regulating microtubule dynamics. Under BDNF stimulation, TrkB is able to activate the Ras/ERK and the PI3K/Akt signaling pathways. On the other hand, activation of p75 activates several intracellular pathways, including the activation of JNK, which may regulate microtubule dynamics. Upon ligand binding, neurotrophin receptors are endocytosed and traffic along the early sorting endosome (EE), late endosomes (LE) and recycling endosomes (not shown). Through the activation of the PI3K/Akt pathway, BDNF regulates microtubule dynamics by the TrkB-dependent phosphorylation of ARMS/Kidins220 that regulates the activity of several microtubule-associated proteins (MAPs) such as MAP1B, MAP2, SCG10 and SCLIP. Also, BDNF/TrkB signaling activates the Ras/ERK pathway, leading to the activation of CREB, which regulates the transcription of the MAP kinase phosphatase MKP-1, the guanine deaminase Cypin (which directly binds to microtubules) and the microRNA miR-9, all of these involved in the regulation of microtubule dynamics. Endosomal trafficking of TrkB receptors plays a key role in the regulation of BDNF/TrkB signaling. For example, TrkB internalization is required for the activation of PI3K/Akt and ERK1/2. In addition, the transition from early to late endosomes is required for the activation of mTOR, since Rheb (a GTPase that directly activates mTOR) localized to late endosomes. Late endosomes have been linked to sustained activation of Rap1/ERK, since BDNF stimulation increases the recruitment of a GEF for Rap1, the Rap1 PDZ-GEF1 to late endosomes. (B) BDNF/TrkB signaling is also involved in the regulation of actin cytoskeleton dynamics. For example, it has been described that activated TrkB receptors can be translocated into lipid rafts, microdomains of the plasma membrane rich in cholesterol and sphingolipids. In lipid raft, TrkB interacts with CL3, a protein kinase anchored to these lipid domains. CL3 role is upstream of the GTPase Rac in BDNF-induced dendritogenesis. Interestingly, Rac is also located in lipid raft and can be activated by Tiam1, a GEF for Rac that is phosphorylated and directly interacts with TrkB receptors. Another Rho protein that regulates actin dynamics is Cdc42, whose activity is regulated by BDNF/TrkB signaling in hippocampal neurons. Activation of Cdc42 by BDNF requires the phosphorylation of TrkB receptors by the protein kinase CDK5. In addition, Cdc 42 may regulate the activity of the non-receptor tyrosine kinase Ack1, a protein that interacts with TrkB receptors and modulates the activation of ERK1/2 and Akt. These pathways play a role in the regulation of the activation of the mTOR kinase, since Akt and ERK1/2 can phosphorylate and inhibits the TSC1/TSC2 protein complex, a GAP for Rheb. Rheb is localized to late endosomes and is required for the activation of mTOR, thus transition from early to late endosomes is required. Activated mTOR can modulate the local translation of specific subsets of mRNA in response to BDNF stimulation, increasing the protein levels of actin-regulators such as Homer2. In the other hand, TrkB.T1, an alternative spliced variant of TrkB receptor that lacks the intracellular kinase domain when unbound by BDNF, binds RhoGDI (a Rho GTPase inhibitor) promoting an increase in RhoA activity. In addition, p75 also can bind RhoGDI in its neurotrophin unbounded state or in complex with the Nogo receptor and myelin-associated proteins. BDNF binding to both receptors releases RhoGDI decreasing the activity of RhoA. 
$\sim 93 \mathrm{kDa}$ truncated isoform lacking the intracellular tyrosine kinase domain (referred to as TrkB.T1), which results from alternative splicing of the $\operatorname{TrkB}$ transcript [Klein et al., 1989, 1990]. Interestingly, there is evidence that coexpression of both isoform aids in sculpting dendritic arbor morphology because TrkB.T1 increases net dendritic length, while TrkB-FL increases proximal dendritic branching in pyramidal cortical neurons of the ferret visual cortex [Yacoubian and Lo, 2000]. TrkB.T1 might also regulate the morphology of other neuronal populations as deletion of TrkB.T1 in mice produced a marked reduction in dendritic branching of neurons from the basolateral amygdala, without any relevant effect on hippocampal morphology [Carim-Todd et al., 2009].

More evidence from both mammals and other vertebrates has shown the involvement of BDNF on axonal arborization in the CNS. Because BDNF-null mice die soon after birth [Jones et al., 1994], the visual circuit of Xenopus laevis has been useful to assess in vivo whether BDNF functions as a short-range signal to stimulate axonal target innervation. Increasing the levels of BDNF in the tectum -the target tissue of retinal ganglion cells (RGC)- revealed that BDNF modulates the morphological maturation of the presynaptic axonal arborization [Cohen-Cory and Fraser, 1995]. Subsequent work by the same group using timelapse confocal microscopy provides direct correlations between dynamic remodeling of synapses and axon arborization by showing that BDNF not only modulates the number of synapses by regulating the morphology of the axonal tree but also promotes synapse formation and maintenance in vivo [Alsina et al., 2001]. As in dendrites [Horch and Katz, 2002], BDNF shows a restricted area of action to increase axonal branching. Huang and colleagues demonstrated that axonal arborization of trigeminal sensory neurons that innervate the cement gland was significantly reduced in embryos with BDNF knockdown early in development; however, it was re-induced when the target tissue was replaced with ectopic grafts expressing BDNF, suggesting that BDNF functions as a short-range molecule to stimulate axon terminal arborization at the target [Huang et al., 2007]. Indeed, the expression of TrkB.T1 on RGC of Xenopus tadpoles affects axonal branching, stability of the axonal arbor and the number of synaptic contacts, but these neurons extend their axons from the retina to the tectum normally, suggesting that TrkB is involved in the BDNFinduced axonal branching but is dispensable to the guidance of axons in the developing visual system [Marshak et al., 2007].

Similar results were found in the mammalian visual system. It was found that TrkB-mediated signaling regulates segregation of thalamic axons in layer IV of the primary visual cortex to form ocular dominance columns in cats [Cabelli et al., 1995; Cabelli et al., 1997]. Additionally, studies conducted in knockout mice with conditional deletion of $\operatorname{TrkB}$ showed a reduced number of pre-synaptic ter- minals and excitatory synapses formed by Schaffer collaterals at the hippocampus, and thalamic neurons lacking TrkB showed aberrations in the number of synaptic terminals and branching [Lush et al., 2005; Luikart et al., 2008]. The role of TrkB in promoting axonal branching in vivo was also corroborated in vitro in different models including hippocampal slice cultures [Danzer et al., 2002] and cortical neurons [Jeanneteau et al., 2010; Panagiotaki et al., 2010; Dajas-Bailador et al., 2012; Granseth et al., 2013]. One interesting observation was that the concentration and lasting effect of BDNF stimulation have different outcomes related to axonal morphology. While brief stimulation of axons with BDNF ( $2 \mathrm{~h}$ with $10 \mathrm{ng} / \mathrm{mL}$ ) promotes axonal growth, prolonged stimulation with a higher concentration of BDNF ( $48 \mathrm{~h}$ with $100 \mathrm{ng} / \mathrm{mL}$ ) produced an increase in the percentage of neurons with more than five branching points, highlighting the importance of prolonged BDNF exposure for structural plasticity [Ji et al., 2010; Dajas-Bailador et al., 2012].

\section{Signaling Pathways Underlying BDNF-Induced Dendritic and Axonal Branching and Cytoskeleton Dynamics}

In polarized cortical neurons, the TrkB-FL receptor is localized in dendrites and axons in the plasma membrane and in intracellular vesicles throughout development [Gomes et al., 2006]. In the plasma membrane, activated TrkB can be translocated into lipid rafts after BDNF stimulation, a step that may be required to induce dendritic branching in cortical neurons since inhibition of cholesterol synthesis -a main component of lipid rafts- inhibits the effects of BDNF on dendritic morphology. However, this result has to be taken with caution since this is a very drastic treatment that can affect the complete plasma membrane [Suzuki et al., 2004]. These lipid domains are the sites where the $\mathrm{Ca}^{2+} /$ calmodulin-dependent protein kinase CLICK-III (also known as CL3 or CaMKI $\gamma$ ) is anchored to the cell surface. CLICK-III plays a critical role in BDNF-induced dendritogenesis [Takemoto-Kimura et al., 2007], suggesting that lipid rafts are an important signaling platform used by BDNF/TrkB to regulate neuronal morphology (see Fig. 1B).

The signaling pathways that regulate BDNF-induced dendritic branching include the activation of the PI3K/ AKT and ERK1/2 signaling pathways as well as the activation of local protein translation by the mTOR (mammalian target of rapamycin) kinase and activation of the Rho GTPase family protein to regulate the actin cytoskeleton [Jaworski et al., 2005; Kumar et al., 2005; Miyamoto et al., 2006]. In addition, activation of PLC $\gamma-1$ appears to be dispensable for increasing dendritic branching but is required to induce hippocampal long-term potentiation [Minichiello 
et al., 2002; Dijkhuizen and Ghosh, 2005]. Several lines of evidence suggest that BDNF increases the local translation of a subset of mRNAs in dendrites, including proteins related to CNS plasticity, while ignoring or even downregulating other transcripts. The detailed mechanism that promotes this selectivity is not known, but includes the regulation of mRNA binding proteins and differential expression of microRNAs [Schratt et al., 2004; Takei et al., 2004; Ruiz et al., 2014]. mTOR regulates protein translation, in part, by phosphorylating the p70 ribosomal S6 protein kinase $1(\mathrm{~S} 6 \mathrm{~K} 1 / 2)$ and the inhibitor of translation 4E-BP1, which increase the translation of a subset of mRNAs containing a 5'CAP in the 5' untranslated region of the mRNA [Lipton and Sahin, 2014]. BDNF also activates local protein synthesis in the axon of cortical neurons in an mTOR dependent manner, but the functional consequence of this process and whether specific transcripts were translated in response to BDNF has yet to be explored [Hsu et al., 2015]. Taken together, these data indicate that BDNF increases dendritic branching by a mechanism that involves dendritic local protein synthesis mediated by activation of the PI3K/Akt/mTOR pathway.

Activation of the ERK1/2 pathway has been extensively described as a downstream mediator of neurotrophic signaling. In the case of TrkB, after BDNF binding, receptor phosphorylation at tyrosine- 515 produces a docking site for Shc and Frs leading to the activation of the Ras-ERK pathway, a signaling pathway that promotes morphological changes in neurons [Dijkhuizen and Ghosh, 2005]. Activation of ERK signaling has been shown to regulate the expression -at the transcriptional level- of serum inducible kinase (SNK, also known as Polo-like kinase 2 PLK2). In this study, the authors showed that SNK is required for BDNF-induced dendritic but not axonal growth [Guo et al., 2012].

While the mechanisms underlying changes in gene expression induced by BDNF/TrkB signaling have not been completely established, as described above, it is known that one of the transcription factors mediating BDNF transcriptional regulation is cAMP response element-binding protein (CREB) [Finkbeiner et al., 1997; Xing et al., 1998]. BDNF and its receptor TrkB regulate gene expression by activating CREB, which is a major mediator of neurotrophin-mediated transcriptional responses, such as early gene expression (c-fos and Arc), in cortical neurons. In addition, CREB is required for BDNF-induced dendritic branching of hippocampal neurons [Kwon et al., 2011]. Finsterwald and colleagues demonstrated that the BDNFinduced increase in dendritic length and branching of cultured cortical neurons depends on the activation of the ERK pathway and phosphorylation of CREB at serine-133 [Finsterwald et al., 2010]. Interestingly, CREB activation is not sufficient to produce morphological changes induced by BDNF, because this also requires binding of the CREB-regulated transcription coactivator (CRTC1), which translocates to the nucleus by a mechanism that depends on NMDA-receptor activation by glutamate [Finsterwald and Martin, 2011]. In addition to BDNF, CREB is activated by several other stimuli regulating dendritic and axonal morphology. In physiological conditions and after cellular injury, activation of CREB increases the intrinsic regenerative capabilities of injured neurons suggesting that BDNF signaling regulates neuronal regeneration [Lonze and Ginty, 2002; Hannila and Filbin, 2008]. Independently from the stimuli that activate CREB, how the activation of this transcription factor is connected with changes in dendritic branching is poorly understood. It has been found that BDNF increases the expression of the guanine deaminase Cypin in a CREB-dependent manner and that Cypin may regulate dendritic branching by direct binding to tubulin heterodimers and promotion of microtubule polymerization [Akum et al., 2004; Kwon et al., 2011] (see Fig. 1A).

The formation of dendrites and axonal branches requires the coordinate action of actin filaments and microtubules and the upstream signaling that regulates their dynamics [Van Aelst and Cline, 2004; Kalil and Dent, 2014]. Therefore, it is not surprising that BDNF/TrkB signaling regulates cytoskeletal dynamics. Actin filament dynamics are regulated by the activity of Rho GTPase family proteins [Gonzalez-Billault et al., 2012]. This family is composed of the small GTPases RhoA, Rac and Cdc42. Similar to most monomeric GTPases, Rho GTPases are active when binding to GTP and their activity is positively regulated by guanine nucleotide exchange factors (GEFs), which are proteins that increase their rate of exchange of GDP by GTP in their active sites. On the other hand, their activity is limited by the hydrolysis of GTP that is facilitated by GTPase-activating proteins (GAPs) and RhoGDI, proteins that prevents their activation by GEFs [Etienne-Manneville and Hall, 2002; Yuan et al., 2003; Van Aelst and Cline, 2004; Myers et al., 2012]. It has been shown that neurite outgrowth requires changes in the actin cytoskeleton in immature cortical neurons [Miyamoto et al., 2006]. This action is based on TrkB-dependent tyrosine phosphorylation of Tiam1, which is a specific GEF of the small GTPase Rac1 favoring actin polymerization. Another Rho GTPase that links cytoskeletal regulation with dendritic branching is Cdc42, which is also activated in response to BDNF stimulation in hippocampal neurons. Activation of Cdc42 requires serine phosphorylation of the juxtamembrane domain of $\operatorname{TrkB}$ mediated by serine/threonine cyclindependent kinase 5 (Cdk5). Although, the GEF involved in Cdc42 activation is currently unknown, phosphorylation of Cdc42 by CDK5 is required to increase the activity of $\mathrm{Cdc} 42$ and the number of primary dendrites in hippocampal neurons. Consistently, a dominant negative mutant of Cdc42 blocks BDNF-induced increase in primary dendrites [Cheung et al., 2007]. In addition to modulating the actin cytoskeleton, Cdc42 modulates the activity of kinases such as Cdc42-associated tyrosine kinase (Ack1), which is a non- 
receptor tyrosine kinase originally characterized as a target of Cdc42 that also participates in BDNF-induced dendritic branching in different neuronal types. Indeed, Ack1 interacts with Trk receptors, but not p75, modulating Akt and ERK activation in the PC12 cell line [La Torre et al., 2013].

BDNF receptors regulate RhoA activity by different means. In the absence of BDNF binding, TrkB.T1 binds RhoGDI, which is a Rho GTPase inhibitor, therefore RhoA activity is increased. However, in the presence of BDNF, RhoGDI dissociates from TrkB.T1 and is available to inhibit Rho activity [Ohira et al., 2006]. Similar mechanisms have been found for $\mathrm{p} 75$ regulation of RhoA activity. When p75 is in a neurotrophin unbound state or when it is in a complex with the Nogo receptor and myelin-associated proteins, RhoGDI is associated with p75 and RhoA activity is increased [Yamashita and Tohyama, 2003]. This process results in the collapse of the growth cone and retraction of axons and dendrites by depolymerizing actin [Wong et al., 2002; Yamashita et al., 2002]. In contrast, when p75 binds neurotrophins, RhoGDI dissociates from p75 and RhoA activity is decreased, and this process favors neurite outgrowth [Yamashita et al., 1999; Gehler et al., 2004]. Interestingly, in cortical neurons, proBDNF also activates RhoA activity through binding to $\mathrm{p} 75$, increasing growth cone collapse and decreasing neurite outgrowth [Sun et al., 2012]. p75 may interact with other signaling complexes to regulate neuronal morphology; indeed, in hippocampal neurons, it has been shown that, when binding to proNGF, p75 and its co-receptor SorCS2 dissociated Trio, a Rac GEF, and inactivates fascin inducing growth cone collapse [Deinhardt et al., 2011]. Interestingly, not just neurotrophins and proneurotrophins are able to regulated actin dynamics. It has been shown that the pro-domain of BDNF is secreted in an activity-dependent manner from neurons and that the variant containing the Val66Met substitution induces growth cone retraction concomitant with reduced Rac activity in hippocampal neurons. Suggesting that the pro-domain of BDNF is a potential new regulator of actin dynamics through p75 [Anastasia et al., 2013]. Another means by which neurotrophins may regulate the actin cytoskeleton is through changes in protein levels of Rho GTPases, which are key proteins that regulate neuronal morphology [Van Aelst and Cline, 2004]. Synaptoneurosomal preparations from mouse neocortex, enriched in synaptic proteins and several mRNAs, has been used to show that RhoA mRNA is located at dendrites, and its protein levels are increased after BDNF stimulation [Troca-Marin et al., 2010]. Indeed, RhoA is required for synaptic plasticity and its protein levels are increased by BDNF activation of mTOR [Murakoshi et al., 2011; Briz et al., 2015]. BDNF also increases the local synthesis of Homer2-other actin regulator-in dendrites of cortical neurons in an mTORdependent manner [Schratt et al., 2004] (see Fig. 1B).

In addition, BDNF may directly regulate actin dynamics through interaction and activation of LIM kinase 1 (LIMK1) regulating both, axon elongation and dendritic ramification. BDNF-induced dimerization of TrkB increases TrkB interaction with LIMK1 in the membrane, process that results in LIMK1 activation and increased axonal growth [Dong et al., 2012]. LIMK1 regulates actin dynamics through the inactivation (by phosphorylation) of the actin-depolymerizing factor $(\mathrm{ADF})$ and cofilin, which are proteins that modulate actin cytoskeletal remodeling by stimulating the depolymerization and severing of actin filaments [Sarmiere and Bamburg, 2004]. Activation of LIMK1 by BDNF depends on the activity of the $\mathrm{Ca}^{2+} /$ Calmodulin kinase $\mathrm{II} \beta$, which directly phosphorylates LIMK1, promoting its cofilinphosphorylating activity, which is required for BDNFinduced primary dendrite formation in cortical neurons [Saito et al., 2013]. Another form by which BDNF can regulates LIMK1 activation is by regulating its protein levels since BDNF inhibits the repression exerted by the miR-134 on LIMK1 translation [Schratt et al., 2006].

In addition to regulating actin dynamics, BDNF also modulates microtubule dynamics. For example, the drug nocodazole (a blocker of microtubule polymerization) decreases the number of primary dendrites in hippocampal neurons, and this is reversed by BDNF stimulation [Chen et al., 2012a], suggesting that BDNF increases microtubule polymerization. BDNF regulates the microtubule cytoskeleton and dendrite morphology by phosphorylation of the transmembrane scaffold protein Ankyrin Repeat-rich Membrane Spanning (ARMS) or Kidins220 (ARMS/Kidins220) via the PI3K/Akt pathway. This process is required for BDNF-induced dendritic development [Wu et al., 2009; Chen et al., 2012b]. ARMS/Kidins220, in addition to specifically regulating neurotrophin signaling [Arevalo et al., 2006], interact with tubulin and several microtubule-associated proteins such as MAP1A, MAP1B and MAP2; and the stathmin family members SCG10 (STMN2) and SCLIP (STMN3), which are proteins that have a well-established role in neuronal morphogenesis [Higuero et al., 2010; Villarroel-Campos and Gonzalez-Billault, 2014]. Particularly, reduction of ARMS/ Kidins220 levels result in decreased phosphorylation of MAP1B and stathmin indicating that ARMS/Kidins220 is likely to increase microtubule stabilization, since the phosphorylation of both proteins increases microtubule stability [Higuero et al., 2010]. Thus, BDNF may exert its regulatory effects on dendrite morphology through the activation of intracellular signaling that includes components such as PI3K/Akt and ARMS/Kidins220 to regulate microtubuleassociated proteins and modify microtubule cytoskeletal dynamics.

Although it is widely reported that $\mathrm{BDNF} / \mathrm{TrkB}$ induces axonal branching [Cohen-Cory et al., 2010], the mechanism underlying this process is not well understood. One report indicated that, in axons, BDNF has a rapid action on cytoskeleton dynamics. Acute application of BDNF to the growth cone of Xenopus spinal neurons showed that there is cooperative activity of microtubules and actin 
filaments that is essential for lamellipodial protrusion. BDNF induces rapid collateral protrusion of filopodiumlike microspikes and lamellipodia along the neurite processes, leading to morphological changes in neuronal structure [Gibney and Zheng, 2003]. It has been shown that the TrkB-Ras-ERK signaling pathway regulates axonal branching by regulating the expression of MAPK phosphatase 1 (MKP1) [Jeanneteau et al., 2010] that negative regulates JNK activity increasing microtubules dynamics [Jeanneteau et al., 2010]. It is known that JNK phosphorylates stathmin and microtubule-associated protein 1B (MAP1B), which stabilizes microtubules [Curmi et al., 1999; Chang et al., 2003]. In vivo, overexpression or down-regulation of MKP1 in layer 2/3 cortical neurons by in utero electroporation increases or decreases their terminal axon branching, respectively, in the contralateral cortex, confirming the in vitro results [Jeanneteau et al., 2010]. It is interesting that both endogenous BDNF and MKP1 expression are upregulated in the brain at later developmental stages, when neuronal networks are refined in an activity-dependent manner [Jeanneteau et al., 2010; Deinhardt and Chao, 2014a]. Another manner by which BDNF regulates axonal branching is by regulating the expression of MAP1B through the expression of microRNA miR-9. Initial signaling by BDNF causes a reduction in miR-9 that relieves the translational repression of map1b, leading to increased expression of the MAP1B protein, microtubule stabilization and axonal growth. On the other hand, prolonged BDNF stimulation increases miR-9 levels in the axon and promotes branching by locally decreasing MAP1B protein expression in vitro [Dajas-Bailador et al., 2012]. In agreement with its role in vitro, miR-9 is found to support axonal development in the mouse cortex. Thus, miR-9 regulates, in a local manner, the levels of MAP1B (see Fig. 1A). Consistently, MAP1B-/- mice have decreased axonal growth and increased axonal branching [Gonzalez-Billault et al., 2001; Dajas-Bailador et al., 2012]. BDNF also regulates the expression of miR-132 to increase axonal branching. miR-132 targets the p250GAP protein, a highly conserved GTPase activating protein that suppresses Rac function [Marler et al., 2014]. Complementing these results, it has been shown in sensory neurons (expressing TrkA and p75) that NGF-induced axonal branching requires the formation of actin patch precursors -driven by the activity of PI3K- and splayed microtubules. Later, invasion of actin filopodia by stable microtubules consolidates the branch. This process requires NGF-mediated phosphorylation and dephosphorylation of MAP1B, which increases microtubule dynamics and further stabilization [Gallo, 2015; Ketschek et al., 2015].

Although there is no direct evidence of the signaling pathways underlying BDNF-mediated axonal branching in the retinotectal system in Xenopus, it has been suggested that ubiquitin-mediated degradation of proteins is relevant for the branching of retinal axons that innervate the optic tec- tum [Drinjakovic et al., 2010]. The authors propose that external signals promote or reduce axon branching by modulating the levels of phosphatase with tensin homolog (PTEN), a phosphatase that opposes PI3K signaling by catalyzing the conversion of phosphatidylinositol 3,4,5-trisphosphate (PIP3) into phosphatidylinositol 4,5-bisphosphate (PIP2) in a Nedd4-dependent manner [Shi et al., 2003]. Nedd4 (neuronal precursor cell expressed developmentally down-regulated protein 4) is an E3 ubiquitin-protein ligase that has been proposed to regulate a number of signaling pathways including insulin signaling [Cao et al., 2008]. An increase in Nedd4 activity results in reduced PTEN levels and therefore promotes the PI3K pathway and downstream cytoskeletal rearrangements that favor branch growth. Consistent with a general role of the PI3K pathway in axonal growth, inhibition of PI3K prevents axonal growth in hippocampal neurons [Shi et al., 2003]. By increasing PI3K activity, BDNF and NT3 promote the phosphorylation and inhibition of the kinase GSK-3 $\beta$, which in turn leads to a reduction in the phosphorylation of CRMP-2 (collapsing response mediator protein 2 ), a protein that is highly expressed in the developing NS and that regulates axonal outgrowth and dendritic branching [Yamashita et al., 2012; Ip et al., 2014]. When dephosphorylated, CRMP-2 binds microtubules promoting microtubule polymerization and axonal growth and branching in cortical neurons [Fukata et al., 2002; Yoshimura et al., 2005]. The phosphorylation of GSK-3 $\beta$ stimulated by BDNF is regulated by Dock3 (a Rac1-GEF), which promotes the recruitment of GSK-3 $\beta$ to the plasma membrane facilitating its phosphorylation by PI3K [Namekata et al., 2012].

There are also reports of negative regulators of BDNFdependent axonal branching. Sprouty3 (Spry3) is a member of the Sprouty (Spry) protein family that are intracellular negative regulators of receptor tyrosine kinase signaling and are involved in numerous developmental processes [Mason et al., 2006]. It has been shown that BDNF/TrkB signaling induces Spry3 expression, possibly via ERK signaling. Spry3 expression inhibits the PLC $\gamma-1 / \mathrm{Ca}^{2+}$ pathway, thereby preventing premature or excess axonal branching, implicating downstream kinases activated by $\mathrm{Ca}^{2+}$ in this process [Panagiotaki et al., 2010].

In summary, BDNF/TrkB signaling modulates both actin and microtubule dynamics to increase dendritic and axonal growth. It does so by triggering the phosphorylation of proteins that regulates Rho GTPases and by controlling local translation of several proteins involved in plasticity. More studies are required to fully understand this complex process.

\section{Membrane Dynamics and the Regulation of BDNF Signaling and Neuronal Morphology}

After ligation, the neurotrophin/receptor complex rapidly activates signaling pathways in the plasma membrane and 
undergoes internalization. It is now well established that the internalization and post-endocytic trafficking of receptors are essential for signaling and neuronal function [Bronfman et al., 2014, and the references therein].

Many lines of research support the idea that the intracellular trafficking of Trks regulates the outcome of neurotrophin signaling. In PC12 cells, the inhibition of dynamin and TRAF6-dependent TrkA internalization inhibits NGFinduced neurite extension [Zhang et al., 2000; Geetha et al., 2005]. The concept that the Trks in the plasma membrane trigger different signaling pathways than those in endosomes came from experiments that demonstrated that plasma membrane TrkA transiently increased Ras (a monomeric GTPase that activates the ERK signaling cascades); however, internalized TrkA interacts with Rap1 (a member of the Ras family of monomeric GTPases) in endosomes, and thereby promotes the sustained activation of the ERK1/2 pathway and neuronal differentiation [York et al., 1998; Mochizuki et al., 2001; Wu et al., 2001]. Consistent with the idea that post-endocytic trafficking of the TrkB receptor is necessary for signaling, inhibition of TrkB internalization reduces PI3K/Akt signaling and neurite outgrowth of hippocampal neurons [Zheng et al., 2008]. Similarly, TrkB recycling, which depends on its kinase activity and the adaptor Hrs, is required for sustained TrkBinduced ERK1/2 signaling [Huang et al., 2009]. On the other hand, retrolinkin, a transmembrane protein highly enriched in early endosomes, and endophilin A1, a protein involved in generating endocytic necks and vesicles during synaptic endocytosis [Huttner and Schmidt, 2000; Masuda et al., 2006], also modulate internalization of TrkB, regulating sustained activation of ERK1/2. Both proteins, retrolinkin and endophilin A1, were required for BDNF-induced morphological changes in the somato-dendritic domain [Liu et al., 2007; Fu et al., 2011]. It has been shown that the transition from early to late endosomes is required for activation of mTOR by insulin signaling since the mTOR GEF, Rheb is located in this organelle [Sancak et al., 2008; Flinn et al., 2010]. It remains to be demonstrated whether this is also true for BDNF-induced activation of mTOR in dendrites and axons. Late endosomes have also been linked to sustained activation of Rap1/ERK since BDNF increases the recruitment of a GEF for Rap1 (PDZ-GEF1) to late endosome, a process required for neurite outgrowth [Hisata et al., 2007]. The upstream mechanism of Rap1 activation by BDNF has not been fully elucidated. However, it is known that BDNF increases the levels of cAMP increasing the activity of EPAC, a guanine-exchanging factor involved in Rap1b activation and neuronal polarity [Cheng et al., 2011; Munoz-Llancao et al., 2015].

Together, these results suggest that $\operatorname{TrkB}$ internalization is required for proper activation of $\mathrm{PI} 3 \mathrm{~K} / \mathrm{Akt} / \mathrm{mTOR}$ and Rap1/ERK signaling most likely through the recruitment of specific adaptors via the endocytic route.
Similar to Trks, p75 is associated with its ligands and interacts with signaling adaptors in endosomes. These endosomes are likely different from the TrkA-positive endosomes because p75 has different kinetics of internalization compared with TrkA [Bronfman et al., 2003; McCaffrey et al., 2009]. In contrast to what has been observed for the Trks, p75 is poorly targeted to the degradative pathway (i.e., late endosomes and lysosomes) [Bronfman et al., 2014]. We have shown that after internalization in PC12 cells and sympathetic neurons, p75 accumulates in the recycling endosomes and multivesicular bodies (MVB) and is ready for exosomal release, which is a ligand-dependent process; therefore, increased internalization augmented the p75 content in exosomes after neuronal depolarization [Escudero et al., 2014]. These results present the interesting possibility that the endocytic pathway is a step to secrete p75 signaling complexes to neighboring cells to propagate signaling in an active circuit as shown for the Evi-exosomes and Wnt signaling pathway in the Drosophila neuromuscular junction [Koles et al., 2012].

Membrane addition for neurite extension is a key aspect of neurite outgrowth and, therefore, the control of membrane dynamics must be part of the downstream actions of neurotrophin signaling for proper regulation of neuronal morphology [Cosker and Segal, 2014]. Among those key components that may regulate intracellular trafficking of receptors and, consequently, neurotrophic signaling are the Rab family of GTPases [Cosker and Segal, 2014; VillarroelCampos et al., 2014]. Rab GTPases are a large family of small GTPases that control membrane identity and vesicle budding, uncoating, motility and fusion through the recruitment of different effector proteins. For this reason, Rabs are major regulators of cellular physiology. For example, Rab5 is a key regulator of early endosomal trafficking, Rab11 and Rab4 regulate transport through the recycling pathway, and Rab7 regulates transit from the early endosomes to the late endosomes and from the late endosomes to the lysosomes. Rab GTPases are central proteins that regulate membrane trafficking and membrane identity by controlling the assembly of cytoplasmic protein complexes at membranes. Similar to the Rho family of GTPases, their activity is regulated by GEFs and GAPs [Stenmark, 2009; Bronfman et al., 2014, and the references therein].

Rab5, 7, and 11 have also been shown to be important for normal neuronal migration and maturation in the cortex through the regulation of $\mathrm{N}$-cadherin trafficking [Kawauchi et al., 2010], revealing a physiological role of the endocytic pathway. This is also true for neuronal morphology because Rab5 activity is necessary for neuronal morphogenesis, specifically by controlling neurite branching in Drosophila in a process that requires dynein transport [Satoh et al., 2008]. Similarly, we have recently shown that Rab11 activity is required for BDNF-mediated dendritic branching in hippocampal neurons [Lazo et al., 2013]. Our results support a model in which dendritic TrkB 
activation increased active Rab11 that associated with its effector, the actin-based motor myosin $\mathrm{Vb}$, which is required for membrane recycling [Roland et al., 2011]. Thus, by increasing the local recycling of $\operatorname{TrkB}$ in dendrites, there is a burst of local BDNF/TrkB signaling and increased dendritic branching [Lazo et al., 2013]. This process has also been observed in vitro in hippocampal synapses, where Rab11 recycling endosomes facilitate the insertion of $\operatorname{TrkB}$ into the synapses and its interaction with the synaptic scaffolding protein PSD95 [Huang et al., 2013]. Supporting a general role for Rab11 in BDNF-mediated dendritic branching, Rab11-mediated recycling was required for optimal BDNF signaling and neurite branching in striatal neurons in a Slitrk5-dependent manner [Song et al., 2015]. Slitrk5 is a cell-surface LRR protein that aids TrkB signaling by facilitating $\operatorname{TrkB}$ recycling through the recruitment of the Rab11 effector Rab11-FIP3 that links the Rab11 GTPase and the cytoplasmic dynein to the recycling pathway [Horgan et al., 2010; Song et al., 2015]. In addition, we have also studied the role of Rab5-positive early endosomes in dendritic branching. The addition of BDNF to hippocampal neurons increases the activity of Rab5 and the mobility of Rab5-positive endosomes in dendrites, and decreasing the activity of Rab5 reduced BDNF-induced dendritic arborization (Gonzalez and Moya-Alvarado, unpublished results). Interestingly, it has been shown that Rab11 also regulates axonal growth in a lemur kinase 1 and CDK5 dependent manner. Down-regulation of lemur kinase 1 activity increased Rab11a traffic to axons and axonal growth [Takano et al., 2012]. Whether Rab11 is involved in BDNF induced axonal growth and branching is a matter for future studies. Together, these results suggest that the BDNF-mediated regulation of neuronal morphology requires the coordinated function of the Rab GTPases in the endocytic pathway, which is regulated by TrkB signaling. Rab GTPases such as Rab5 and Rab11 have been shown to regulate physiological processes such as cellular migration, thereby regulating actin filament dynamics through activation of Racl activity. This suggests that cytoskeleton dynamics required for neuronal growth may also require intracellular activation of Rho GTPases [Assaker et al., 2010; Emery and Ramel, 2013; Chen et al., 2014]. Thus, Rab GTPases, most likely by regulating intracellular trafficking, coordinate different aspects of neuronal growth allowing for local control of signaling and cytoskeleton dynamics or long-distance signaling in axons (see below).

Despite the fact that some Rab proteins are involved in the proper development of the NS and in the regulation of the morphology of neurons, little is known about the signaling pathways that regulate their activity and more work has to be done to integrate membrane dynamics regulated by Rab GTPases and the parallel signaling pathways that are activated by neurotrophin receptors [Satoh et al., 2008; Kawauchi et al., 2010; Mori et al., 2012; Mori et al., 2013; Zou et al., 2015].
There is additional evidence indicating that the endocytic system is important for proper dendritic development. The role of $\mathrm{Na}^{+} / \mathrm{H}^{+}$exchanger 6 (NHE6), which is one of the most commonly mutated genes causing X-linked developmental brain disorders, has revealed the regulation of endosomal $\mathrm{pH}$ as a key aspect regulating endocytic neurotrophin signaling and possibly other cellular processes and signaling pathways. NHE6 regulates the intracellular $\mathrm{pH}$, maintaining higher $\mathrm{pH}$ values $(\sim 6.2)$ compared to lysosomes $(\mathrm{pH}$ ) in early and recycling endosomes and allowing for sustained intracellular BDNF/TrkB signaling and avoiding faster TrkB degradation. Consistently, loss of function of NHE6 impairs axonal and dendritic branching in hippocampal neurons [Ouyang et al., 2013].

As stated in "Introduction" section, neurotrophins were first discovered as target-derived factors. The question then arises as to how the neurotrophin signals are propagated from the axon to the cell body and whether this signaling is required for proper neuronal functions. More than two decades of studies have supported the notion that neurotrophins, upon ligand-binding in the axonal terminal, increase signaling endosomes containing activated Trks receptors and signaling molecules to convey cellular responses in the nucleus [Harrington and Ginty, 2013]. It has been demonstrated that both the kinase activity and internalization of Trks are required for the retrograde transport of nuclear responses, including the activation of transcription factors such as CREB and c-fos. Furthermore, the inhibition of dynein activity and endocytosis in the axons of the compartmentalized sensory neuron cultures causes downregulation of the transport of activated Trks together with inhibition of the survival responses in the cell body [Heerssen et al., 2004; Ascano et al., 2012; Bronfman et al., 2014, and references therein]. Furthermore, a direct interaction of Trks with the molecular motor dynein, as described by Chao and coworkers [Yano et al., 2001], and ERK1/2dependent dynein-mediated transport of $\operatorname{TrkB}$ in Rab7 endosomes suggest that local $\operatorname{TrkB}$ activation in axons triggers retrograde transport of signaling endosomes containing activated TrkB [Mitchell et al., 2012]. Early work in other models such as the sciatic nerve also supports a signaling endosome as a carrier of retrograde signaling in the NS. Endosomes derived from the sciatic nerve axoplasm containing activated TrkA, p75, phospho-ERK1/2, PI3K, phospho-p38 and Rap1 were described [Delcroix et al., 2003]. Other mechanisms have been postulated for the propagation of neurotrophin signaling along the axon [Harrington and Ginty, 2013; Bronfman et al., 2014, and the references therein]. However, the molecular mechanism with the most experimental validation is the "signaling endosome model" [Ye et al., 2003; Bronfman et al., 2014, and the references therein].

Rab GTPases also function in the axon and likely regulate retrograde signaling by neurotrophic factors. The nature of the transported organelle that mediates retrograde 
neurotrophin signaling has been a controversial issue, and the most probable explanation is that there is a mixed population of different types of endosomes that depend on the neuronal type and the signal generated. Mobley and collaborators characterized an early endosomal fraction (Rab5and EEA1-positive) derived from the sciatic nerve axoplasm that contained activated TrkA receptors and activated signaling molecules [Delcroix et al., 2003]. Another report also associates a Rab5-positive multivesicular endosome/ body (MVBs) as a retrograde carrier [Philippidou et al., 2011]. An elegant study performed by Schiavo and collaborators provided evidence that the Rab5 GTPase is important for sorting vesicles to the retrograde transport pathway in the axon of motor neurons [Deinhardt et al., 2006]. However, they found that the Rab7 GTPase, a classical marker of late endosomes, was necessary for the retrograde transport of an organelle positive for $\mathrm{p} 75$ and TrkB in motor neurons. Notably, the Rab5, Rab7, and Rab11 GTPases have all been functionally linked to molecular motor-mediated transport, including dynein- and kinesinmediated transport, and signaling organelles in the axon [Bronfman et al., 2014, and the references therein]. Additional research will be required to understand the heterogeneity of the different signaling organelles and the molecular machinery that generates them and regulates their transport.

Long-distance signaling from the target tissues to induce transcriptional changes in the soma is well described in the PNS [Harrington and Ginty, 2013]. However, the longdistance effects of target-derived neurotrophins, such as BDNF, in the CNS are far less studied, and contribution of retrograde signaling to the transcriptional and morphological changes has rarely been reported. The retrograde transport of BDNF in the CNS has been investigated by intraparenchymal injection of BDNF; significant levels of BDNF were retrogradely transported (from axons to cell bodies) in the NS [Mufson et al., 1999]. Some studies have suggested retrograde effects of BDNF in the CNS. For example, in a primate spinal cord injury model, it was shown that axotomized corticospinal neurons (the cell body is located in the cortex) show local effects on axonal growth, and remote retrograde effects resulted in significant reductions in axotomy-induced neuronal cell atrophy after gene delivery of BDNF into the lesion sites in the spinal cord [Brock et al., 2010]. In the retinotectal circuit in X. laevis, an infusion of BDNF in the optic tectum promoted local axonal growth of retinal ganglion neurons (RGC) but also increased the arborization of RGCs in the retina, which resulted in potentiation of the RGC synapses with the bipolar cells in the retina and increased their sensitivity to a stimulus. When BDNF was applied directly to the dendrites, BDNF inhibited their growth, suggesting that longdistance signaling may have different cellular outcomes than the signaling initiated in the dendrites or soma [Lom et al., 2002; Du and Poo, 2004].
Long-distance retrograde transport of $\operatorname{TrkB}$ has been described in striatal dendrites. This process requires Huntingtin (HTT), a protein that regulates dynein-dependent transport. Consistent with the requirement of long-distance signaling of the TrkB receptor, mutated HTT (the mutation causing Huntington's Disease) reduced ERK activation and c-fos expression in response to BDNF [Liot et al., 2013]. Additionally, long-distance signaling has been observed from distal dendrites. Dendritic activation by BDNF and retrograde signaling to the cell body was also shown to increase Arc and c-fos expression, whereas axonal stimulation did not have an effect on the expression of these early genes [Cohen et al., 2011]. Similarly, disrupting the snapin/dynein interaction reduced $\operatorname{TrkB}$ retrograde transport and dendritic growth in cortical neurons. It was not established whether this effect was due to reduced retrograde transport from the dendrites or axons [Zhou et al., 2012]. However, it has been shown that the addition of BDNF to axons induced retrograde activation of CREB [Zhou et al., 2012; Bronfman et al., 2014]. Together, these results suggest that, in addition to the local effect of BDNF in axonal growth described above, BDNF in axons may generate a signaling endosome that regulates transcription and dendritic plasticity at the cell body. It is not known whether these signaling endosomes are regulated by Rab5-Rab7 or Rab5Rab11 mediated process. In sympathetic neurons, retrograde signaling of NGF/TrkA increases the transcytosis of somatic TrkA receptors to the axons increasing axonal growth, which is dependent on the activity of Rab11 [Ascano et al., 2009]. On the other hand, Rab5-Rab7mediated transport was described in motor neurons, Rab7/ TrkB organelles have been shown to traffic together in the axons of cortical neurons, and other receptors used Rab7positive endosomes for retrograde transport [Zhou et al., 2012; Schmieg et al., 2014]. Taken together, these studies indicate a prominent role of Rab GTPases in BDNF axonal signaling and indicate that more studies are required to understand how BDNF/TrkB regulates Rab activity and membrane dynamics.

\section{Concluding Remarks}

The role of BDNF/TrkB in regulating axonal and dendritic growth is well established, and several circuits including the cortico-callosal and cortico-striatal pathways are proven to rely heavily on both TrkB and p75 signaling for both dendritic and axonal growth and maintenance. Neurotrophins including BDNF are secreted from the soma but also in the distal part of the neurons signaling locally or triggering long-distance signaling from axons or dendrites back to the nucleus. In general, the control of neuronal growth relies on the PI3K/AKT signaling pathway regulating both cytoskeleton dynamics and local synthesis of proteins in axons and dendrites in an mTOR-dependent manner. On the other hand, sustained ERK signaling increases the 
activation of CREB and regulates the transcription of genes required for dendritic growth including proteins that regulate cytoskeleton dynamics such as Arc and Cypin. Several studies in the literature indicate that BDNF receptors signal in intracellular organelles and that this process is regulated by Rab GTPases. The regulation in this case is bidirectional TrkB signaling regulates Rab activity and Rab activity impacts neuronal morphology. However, how signaling initiated by BDNF simultaneous coordinates membrane trafficking, cytoskeleton dynamics and local protein synthesis to regulate neuronal morphology has just started to emerge and should be a matter of future studies. Particularly, it will be interesting to dissect the contribution of different endosomal populations that allow BDNF receptors trafficking regulating both, local and long-distance signaling. The role of long-distance signaling in regulating neuronal growth and plasticity is not well documented in the CNS and should be better delineated in the future. The evidences from the PNS indicates that it is likely that BDNF signaling in the CNS regulates Rab GTPase activity and endosomal trafficking for proper local (regulating cytoskeleton dynamics) and long-distance signaling (regulating transcription of genes), which are both required for neuronal growth. These studies form the basis of an interesting field that should uncover the molecular machinery that is required for proper intracellular signaling in neurons that have to integrate the signals that are generated in the soma, dendrites and axons for circuitry maintenance.

\section{Acknowledgments}

FB was supported by Fondecyt (Grant 1120146), Basal center of excellence in science and technology (PFB-12/2007) and Millenium Nucleus of Regenerative Biology, MINREB, (P07/011-F). CGB was supported by Fondecyt (Grant 1140325) and FONDAP Program (Grant 15150012). AG and GMA are or were supported by $\mathrm{PhD}$ doctoral fellowships from Fondecyt.

\section{References}

Akum BF, Chen M, Gunderson SI, Riefler GM, Scerri-Hansen MM, Firestein BL. 2004. Cypin regulates dendrite patterning in hippocampal neurons by promoting microtubule assembly. Nat Neurosci 7:145-152.

Alsina B, Vu T, Cohen-Cory S. 2001. Visualizing synapse formation in arborizing optic axons in vivo: Dynamics and modulation by BDNF. Nat Neurosci 4:1093-1101.

Anastasia A, Deinhardt K, Chao MV, Will NE, Irmady K, Lee FS, Hempstead BL, Bracken C. 2013. Val66Met polymorphism of $\mathrm{BDNF}$ alters prodomain structure to induce neuronal growth cone retraction. Nat Commun 4:2490.

Arevalo JC, Pereira DB, Yano H, Teng KK, Chao MV. 2006. Identification of a switch in neurotrophin signaling by selective tyrosine phosphorylation. J Biol Chem 281:1001-1007.

Armstrong DD, Dunn K, Antalffy B. 1998. Decreased dendritic branching in frontal, motor and limbic cortex in Rett syndrome compared with trisomy 21. J Neuropathol Exp Neurol 57:10131017.
Ascano M, Richmond A, Borden P, Kuruvilla R. 2009. Axonal targeting of Trk receptors via transcytosis regulates sensitivity to neurotrophin responses. J Neurosci 29:11674-11685.

Ascano M, Bodmer D, Kuruvilla R. 2012. Endocytic trafficking of neurotrophins in neural development. Trend Cell Biol 22:266-273.

Assaker G, Ramel D, Wculek SK, Gonzalez-Gaitan M, Emery G. 2010. Spatial restriction of receptor tyrosine kinase activity through a polarized endocytic cycle controls border cell migration. Proc Natl Acad Sci U S A 107:22558-22563.

Baquet ZC, Gorski JA, Jones KR. 2004. Early striatal dendrite deficits followed by neuron loss with advanced age in the absence of anterograde cortical brain-derived neurotrophic factor. J Neurosci 24:4250-4258.

Briz V, Zhu G, Wang Y, Liu Y, Avetisyan M, Bi X, Baudry M. 2015. Activity-dependent rapid local RhoA synthesis is required for hippocampal synaptic plasticity. J Neurosci 35:2269-2282.

Brock JH, Rosenzweig ES, Blesch A, Moseanko R, Havton LA, Edgerton VR, Tuszynski MH. 2010. Local and remote growth factor effects after primate spinal cord injury. J Neurosci 30:97289737.

Bronfman FC, Tcherpakov M, Jovin TM, Fainzilber M. 2003. Ligand-induced internalization of the p75 neurotrophin receptor: A slow route to the signaling endosome. J Neurosci 23:3209-3220.

Bronfman FC, Escudero CA, Weis J, Kruttgen A. 2007. Endosomal transport of neurotrophins: Roles in signaling and neurodegenerative diseases. Dev Neurobiol 67:1183-1203.

Bronfman FC, Lazo OM, Flores C, Escudero CA. 2014. Spatiotemporal intracellular dynamics of neurotrophin and its receptors. Implications for neurotrophin signaling and neuronal function. Handb Exp Pharmacol 220:33-65.

Bruns MB, Miller MW. 2007. Neurotrophin ligand-receptor systems in somatosensory cortex of adult rat are affected by repeated episodes of ethanol. Exp Neurol 204:680-692.

Cabelli RJ, Hohn A, Shatz CJ. 1995. Inhibition of ocular dominance column formation by infusion of NT-4/5 or BDNF. Science 267:1662-1666.

Cabelli RJ, Shelton DL, Segal RA, Shatz CJ. 1997. Blockade of endogenous ligands of trkB inhibits formation of ocular dominance columns. Neuron 19:63-76.

Cabeza C, Figueroa A, Lazo OM, Galleguillos C, Pissani C, Klein A, Gonzalez-Billault C, Inestrosa NC, Alvarez AR, Zanlungo S, Bronfman FC. 2012. Cholinergic abnormalities, endosomal alterations and up-regulation of nerve growth factor signaling in Niemann-Pick type C disease. Mol Neurodegener 7:11.

Cao XR, Lill NL, Boase N, Shi PP, Croucher DR, Shan H, Qu J, Sweezer EM, Place T, Kirby PA, Daly RJ, Kumar S, Yang B. 2008. Nedd4 controls animal growth by regulating IGF-1 signaling. Sci Signal 1:ra5.

Carim-Todd L, Bath KG, Fulgenzi G, Yanpallewar S, Jing D, Barrick CA, Becker J, Buckley H, Dorsey SG, Lee FS, Tessarollo L. 2009. Endogenous truncated TrkB.T1 receptor regulates neuronal complexity and TrkB kinase receptor function in vivo. J Neurosci 29:678-685.

Chang L, Jones Y, Ellisman MH, Goldstein LS, Karin M. 2003. JNK1 is required for maintenance of neuronal microtubules and controls phosphorylation of microtubule-associated proteins. Dev Cell 4:521-533.

Chen Q, Zhou Z, Zhang L, Wang Y, Zhang YW, Zhong M, Xu SC, Chen CH, Li L, Yu ZP. 2012a. Tau protein is involved in morphological plasticity in hippocampal neurons in response to BDNF. Neurochem Int 60:233-242. 
Chen Y, Fu WY, Ip JP, Ye T, Fu AK, Chao MV, Ip NY. 2012b. Ankyrin repeat-rich membrane spanning protein (kidins220) is required for neurotrophin and ephrin receptor-dependent dendrite development. J Neurosci 32:8263-8269.

Chen PI, Schauer K, Kong C, Harding AR, Goud B, Stahl PD. 2014. Rab5 isoforms orchestrate a "division of labor" in the endocytic network; Rab5C modulates Rac-mediated cell motility. PloS One 9:e90384.

Cheng PL, Song AH, Wong YH, Wang S, Zhang X, Poo MM. 2011. Self-amplifying autocrine actions of BDNF in axon development. Proc Natl Acad Sci U S A 108:18430-18435.

Cheung ZH, Chin WH, Chen Y, Ng YP, Ip NY. 2007. Cdk5 is involved in BDNF-stimulated dendritic growth in hippocampal neurons. PLoS Biol 5:e63.

Cohen MS, C, Bas Orth HJ Kim NL. Jeon SR, Jaffrey 2011. Neurotrophin-mediated dendrite-to-nucleus signaling revealed by microfluidic compartmentalization of dendrites. Proc Natl Acad Sci U S A 108:11246-11251.

Cohen-Cory S, Fraser SE. 1995. Effects of brain-derived neurotrophic factor on optic axon branching and remodelling in vivo. Nature 378:192-196.

Cohen-Cory S, Kidane AH, Shirkey NJ, Marshak S. 2010. Brainderived neurotrophic factor and the development of structural neuronal connectivity. Dev Neurobiol 70:271-288.

Cosker KE, Segal RA. 2014. Neuronal signaling through endocytosis. Cold Spring Harbor Perspect Biol 6:

Curmi PA, Gavet O, Charbaut E, Ozon S, Lachkar-Colmerauer S, Manceau V, Siavoshian S, Maucuer A, Sobel A. 1999. Stathmin and its phosphoprotein family: General properties, biochemical and functional interaction with tubulin. Cell Struct Funct 24:345-357.

Dajas-Bailador F, Bonev B, Garcez P, Stanley P, Guillemot F, Papalopulu N. 2012. microRNA-9 regulates axon extension and branching by targeting Map1b in mouse cortical neurons. Nat Neurosci 15:697-699.

Danzer SC, Crooks KR, Lo DC, McNamara JO. 2002. Increased expression of brain-derived neurotrophic factor induces formation of basal dendrites and axonal branching in dentate granule cells in hippocampal explant cultures. J Neurosci 22:9754-9763.

Dean C, Liu H, Staudt T, Stahlberg MA, Vingill S, Buckers J, Kamin D, Engelhardt J, Jackson MB, Hell SW, Chapman ER. 2012. Distinct subsets of Syt-IV/BDNF vesicles are sorted to axons versus dendrites and recruited to synapses by activity. J Neurosci 32:5398-5413.

Deinhardt K, Chao MV. 2014a. Shaping neurons: Long and short range effects of mature and proBDNF signalling upon neuronal structure. Neuropharmacology 76 Pt C:603-609.

Deinhardt K, Chao MV. 2014b. Trk receptors. Handb Exp Pharmacol 220:103-119.

Deinhardt K, Salinas S, Verastegui C, Watson R, Worth D, Hanrahan S, Bucci C, Schiavo G. 2006. Rab5 and Rab7 control endocytic sorting along the axonal retrograde transport pathway. Neuron 52:293-305.

Deinhardt K, Kim T, Spellman DS, Mains RE, Eipper BA, Neubert TA, Chao MV, Hempstead BL. 2011. Neuronal growth cone retraction relies on proneurotrophin receptor signaling through Rac. Sci Signal 4:ra82.

Delcroix JD, Valletta JS, Wu C, Hunt SJ, Kowal AS, Mobley WC. 2003. NGF signaling in sensory neurons: Evidence that early endosomes carry NGF retrograde signals. Neuron 39:69-84.

Dickstein DL, Brautigam H, Stockton SD, Jr.,Schmeidler J, Hof PR. 2010. Changes in dendritic complexity and spine morphology in transgenic mice expressing human wild-type tau. Brain Struct Funct 214:161-179.

Dijkhuizen PA, Ghosh A. 2005. BDNF regulates primary dendrite formation in cortical neurons via the PI3-kinase and MAP kinase signaling pathways. J Neurobiol 62:278-288.

Dong Q, Ji YS, Cai C, Chen ZY. 2012. LIM kinase 1 (LIMK1) interacts with tropomyosin-related kinase $\mathrm{B}(\mathrm{TrkB})$ and mediates brain-derived neurotrophic factor (BDNF)-induced axonal elongation. J Biol Chem 287:41720-41731.

Drinjakovic J, Jung H, Campbell DS, Strochlic L, Dwivedy A, Holt CE. 2010. E3 ligase Nedd4 promotes axon branching by downregulating PTEN. Neuron 65:341-357.

Du JL, Poo MM. 2004. Rapid BDNF-induced retrograde synaptic modification in a developing retinotectal system. Nature 429:878883.

Edelmann E, Lessmann V, Brigadski T. 2014. Pre- and postsynaptic twists in BDNF secretion and action in synaptic plasticity. Neuropharmacology 76 Pt C:610-627.

Eiland L, McEwen BS. 2012. Early life stress followed by subsequent adult chronic stress potentiates anxiety and blunts hippocampal structural remodeling. Hippocampus 22:82-91.

Emery G, Ramel D. 2013. Cell coordination of collective migration by Rab11 and Moesin. Commun Integr Biol 6:e24587.

Escudero CA, Lazo OM, Galleguillos C, Parraguez JI, LopezVerrilli MA, Cabeza C, Leon L, Saeed U, Retamal C, Gonzalez A, Marzolo MP, Carter BD, Court FA, Bronfman FC. 2014. The p75 neurotrophin receptor evades the endolysosomal route in neuronal cells, favouring multivesicular bodies specialised for exosomal release. J Cell Sci 127:1966-1979.

Etienne-Manneville S, Hall A. 2002. Rho GTPases in cell biology. Nature 420:629-635.

Finkbeiner S, Tavazoie SF, Maloratsky A, Jacobs KM, Harris KM, Greenberg ME. 1997. CREB: A major mediator of neuronal neurotrophin responses. Neuron 19:1031-1047.

Finsterwald C, Martin JL. 2011. Cellular mechanisms underlying the regulation of dendritic development by hepatocyte growth factor. Eur J Neurosci 34:1053-1061.

Finsterwald C, H Fiumelli JR. Cardinaux JL, Martin 2010. Regulation of dendritic development by BDNF requires activation of CRTC1 by glutamate. J Biol Chem 285:28587-28595.

Flavell SW, Greenberg ME. 2008. Signaling mechanisms linking neuronal activity to gene expression and plasticity of the nervous system. Ann Rev Neurosci 31:563-590.

Flinn RJ, Yan Y, Goswami S, Parker PJ, Backer JM. 2010. The late endosome is essential for mTORC1 signaling. Mol Biol Cell 21: 833-841.

Fu X, Yang Y, Xu C, Niu Y, Chen T, Zhou Q, Liu JJ. 2011. Retrolinkin cooperates with endophilin A1 to mediate BDNF-TrkB early endocytic trafficking and signaling from early endosomes. Mol Biol Cell 22:3684-3698.

Fukata Y, Itoh TJ, Kimura T, Menager C, Nishimura T, Shiromizu T, Watanabe $\mathrm{H}$, Inagaki $\mathrm{N}$, Iwamatsu A, Hotani H, Kaibuchi K. 2002. CRMP-2 binds to tubulin heterodimers to promote microtubule assembly. Nat Cell Biol 4:583-591.

Gallo G. 2015. Localized regulation of the axon shaft during the emergence of collateral branches. Neural Regen Res 10:1206-1208.

Gao FB. 2007. Molecular and cellular mechanisms of dendritic morphogenesis. Curr Opin Neurobiol 17:525-532.

Gauthier LR, Charrin BC, Borrell-Pages M, Dompierre JP, Rangone H, Cordelieres FP, De Mey J, MacDonald ME, Lessmann V, Humbert S, Saudou F. 2004. Huntingtin controls neurotrophic 
support and survival of neurons by enhancing BDNF vesicular transport along microtubules. Cell 118:127-138.

Geetha T, Jiang J, Wooten MW. 2005. Lysine 63 polyubiquitination of the nerve growth factor receptor TrkA directs internalization and signaling. Mol Cell 20:301-312.

Gehler S, Gallo G, Veien E, Letourneau PC. 2004. p75 neurotrophin receptor signaling regulates growth cone filopodial dynamics through modulating RhoA activity. J Neurosci 24:4363-4372.

Gibney J, Zheng JQ. 2003. Cytoskeletal dynamics underlying collateral membrane protrusions induced by neurotrophins in cultured Xenopus embryonic neurons. J Neurobiol 54:393-405.

Glebova NO, Ginty DD. 2005. Growth and survival signals controlling sympathetic nervous system development. Annu Rev Neurosci 28:191-222.

Gomes RA, Hampton C, El-Sabeawy F, Sabo SL, McAllister AK. 2006. The dynamic distribution of TrkB receptors before, during, and after synapse formation between cortical neurons. J Neurosci 26:11487-11500.

Gonzalez-Billault C, Avila J, Caceres A. 2001. Evidence for the role of MAP1B in axon formation. Mol Biol Cell 12:2087-2098.

Gonzalez-Billault C, Munoz-Llancao P, Henriquez DR, Wojnacki J, Conde C, Caceres A. 2012. The role of small GTPases in neuronal morphogenesis and polarity. Cytoskeleton (Hoboken) 69:464-485.

Gorski JA, SR Zeiler S. Tamowski KR, Jones 2003. Brain-derived neurotrophic factor is required for the maintenance of cortical dendrites. J Neurosci 23:6856-6865.

Granseth B, Fukushima Y, Sugo N, Lagnado L, Yamamoto N. 2013. Regulation of thalamocortical axon branching by BDNF and synaptic vesicle cycling. Front Neural Circuit 7:202.

Guillemard V, Ivanisevic L, Garcia AG, Scholten V, Lazo OM, Bronfman FC, Saragovi HU. 2010. An agonistic mAb directed to the $\mathrm{TrkC}$ receptor juxtamembrane region defines a trophic hot spot and interactions with p75 coreceptors. Dev Neurobiol 70:150-164.

Guo SL, Tan GH, Li S, Cheng XW, Zhou Y, Jia YF, Xiong H, Tao J, Xiong ZQ. 2012. Serum inducible kinase is a positive regulator of cortical dendrite development and is required for BDNFpromoted dendritic arborization. Cell Res 22:387-398.

Hannila SS, Filbin MT. 2008. The role of cyclic AMP signaling in promoting axonal regeneration after spinal cord injury. Exp Neurol 209:321-332.

Harrington AW, Ginty DD. 2013. Long-distance retrograde neurotrophic factor signalling in neurons. Nat Rev Neurosci 14:177-187.

Heerssen HM, Pazyra MF, Segal RA. 2004. Dynein motors transport activated Trks to promote survival of target-dependent neurons. Nat Neurosci 7:596-604.

Hempstead BL. 2014. Deciphering proneurotrophin actions. Handb Exp Pharmacol 220:17-32.

Higuchi H, Yamashita T, Yoshikawa H, Tohyama M. 2003. PKA phosphorylates the p75 receptor and regulates its localization to lipid rafts. EMBO J 22:1790-1800.

Higuero AM, Sanchez-Ruiloba L, Doglio LE, Portillo F, AbadRodriguez J, Dotti CG, Iglesias T. 2010. Kidins220/ARMS modulates the activity of microtubule-regulating proteins and controls neuronal polarity and development. J Biol Chem 285:1343-1357.

Hisata S, Sakisaka T, Baba T, Yamada T, Aoki K, Matsuda M, Takai Y. 2007. Rap1-PDZ-GEF1 interacts with a neurotrophin receptor at late endosomes, leading to sustained activation of Rap1 and ERK and neurite outgrowth. J Cell Biol 178:843-860.

Horch HW, Katz LC. 2002. BDNF release from single cells elicits local dendritic growth in nearby neurons. Nat Neurosci 5:11771184.
Horgan CP, SR, Hanscom RS Jolly CE. Futter MW, McCaffrey 2010. Rab11-FIP3 links the Rab11 GTPase and cytoplasmic dynein to mediate transport to the endosomal-recycling compartment. J Cell Sci 123:181-191.

Horton AC, Ehlers MD. 2004. Secretory trafficking in neuronal dendrites. Nat Cell Biol 6:585-591.

Hsu WL, Chung HW, Wu CY, Wu HI, Lee YT, Chen EC, Fang W, Chang YC. 2015. Glutamate stimulates local protein synthesis in the axons of rat cortical neurons by activating alpha-Amino-3hydroxy-5-methyl-4-isoxazolepropionic acid (AMPA) receptors and metabotropic glutamate receptors. J Biol Chem 290:20748-20760.

Huang EJ, Reichardt LF. 2001. Neurotrophins: Roles in neuronal development and function. Ann Rev Neurosci 24:677-736.

Huang EJ, Reichardt LF. 2003. Trk receptors: Roles in neuronal signal transduction. Ann Rev Biochem 72:609-642.

Huang JK, Dorey K, Ishibashi S, Amaya E. 2007. BDNF promotes target innervation of Xenopus mandibular trigeminal axons in vivo. BMC Dev Biol 7:59.

Huang SH, Zhao L, Sun ZP, Li XZ, Geng Z, Zhang KD, Chao MV, Chen ZY. 2009. Essential role of Hrs in endocytic recycling of full-length TrkB receptor but not its isoform TrkB.T1. J Biol Chem 284:15126-15136.

Huang SH, Wang J, Sui WH, Chen B, Zhang XY, Yan J, Geng Z, Chen ZY. 2013. BDNF-dependent recycling facilitates TrkB translocation to postsynaptic density during LTP via a Rab11-dependent pathway. J Neurosci 33:9214-9230.

Huttner WB, Schmidt A. 2000. Lipids, lipid modification and lipid-protein interaction in membrane budding and fission-insights from the roles of endophilin A1 and synaptophysin in synaptic vesicle endocytosis. Curr Opin Neurobiol 10:543-551.

Ip JP, Fu AK, Ip NY. 2014. CRMP2: Functional roles in neural development and therapeutic potential in neurological diseases. Neuroscientist 20:589-598.

Jan YN, Jan LY. 2010. Branching out: Mechanisms of dendritic arborization. Nat Rev Neurosci 11:316-328.

Jaworski J, Spangler S, Seeburg DP, Hoogenraad CC, Sheng M. 2005. Control of dendritic arborization by the phosphoinositide-3'kinase-Akt-mammalian target of rapamycin pathway. J Neurosci 25: 11300-11312.

Jeanneteau F, Deinhardt K, Miyoshi G, Bennett AM, Chao MV. 2010. The MAP kinase phosphatase MKP-1 regulates BDNFinduced axon branching. Nat Neurosci 13:1373-1379.

Ji Y, Lu Y, Yang F, Shen W, Tang TT, Feng L, Duan S, Lu B. 2010. Acute and gradual increases in BDNF concentration elicit distinct signaling and functions in neurons. Nat Neurosci 13:302-309.

Jones KR, Farinas I, Backus C, Reichardt LF. 1994. Targeted disruption of the BDNF gene perturbs brain and sensory neuron development but not motor neuron development. Cell 76:989-999.

Kalil K, Dent EW. 2014. Branch management: Mechanisms of axon branching in the developing vertebrate CNS. Nat Rev Neurosci 15:7-18.

Kaplan DR, Miller FD. 2000. Neurotrophin signal transduction in the nervous system. Curr Opin Neurobiol 10:381-391.

Kawauchi T, Sekine K, Shikanai M, Chihama K, Tomita K, Kubo K, Nakajima K, Nabeshima Y, Hoshino M. 2010. Rab GTPasesdependent endocytic pathways regulate neuronal migration and maturation through N-cadherin trafficking. Neuron 67:588-602.

Ketschek A, Jones S, Spillane M, Korobova F, Svitkina T, Gallo G. 2015. Nerve growth factor promotes reorganization of the axonal microtubule array at sites of axon collateral branching. Dev Neurobiol 75:1441-1461. 
Klein R, Parada LF, Coulier F, Barbacid M. 1989. trkB, a novel tyrosine protein kinase receptor expressed during mouse neural development. EMBO J 8:3701-3709.

Klein R, Conway D, Parada LF, Barbacid M. 1990. The trkB tyrosine protein kinase gene codes for a second neurogenic receptor that lacks the catalytic kinase domain. Cell 61:647-656.

Koles K, Nunnari J, Korkut C, Barria R, Brewer C, Li Y, Leszyk J, Zhang B, Budnik V. 2012. Mechanism of evenness interrupted (Evi)-exosome release at synaptic boutons. J Biol Chem 287: $16820-16834$.

Kraemer BR, Yoon SO, Carter BD. 2014. The biological functions and signaling mechanisms of the p75 neurotrophin receptor. Handb Exp Pharmacol 220:121-164.

Kulkarni VA, Firestein BL. 2012. The dendritic tree and brain disorders. Mol Cell Neurosci 50:10-20.

Kumar V, Zhang MX, Swank MW, Kunz J, Wu GY. 2005. Regulation of dendritic morphogenesis by Ras-PI3K-Akt-mTOR and RasMAPK signaling pathways. J Neurosci 25:11288-11299.

Kwon M, JR, Fernandez GF Zegarek SB. Lo BL, Firestein 2011. BDNF-promoted increases in proximal dendrites occur via CREBdependent transcriptional regulation of cypin. J Neurosci 31:97359745.

La Torre A, del Mar Masdeu M, Cotrufo T, Moubarak RS, del Rio JA, Comella JX, Soriano E, Urena JM. 2013. A role for the tyrosine kinase ACK1 in neurotrophin signaling and neuronal extension and branching. Cell Death Dis 4:e602.

Lazo OM, Gonzalez A, Ascano M, Kuruvilla R, Couve A, Bronfman FC. 2013. BDNF regulates Rab11-mediated recycling endosome dynamics to induce dendritic branching. J Neurosci 33: 6112-6122.

Levi-Montalcini R. 1987. The nerve growth factor 35 years later. Science 237:1154-1162.

Liot G, Zala D, Pla P, Mottet G, Piel M, Saudou F. 2013. Mutant Huntingtin alters retrograde transport of TrkB receptors in striatal dendrites. J Neurosci 33:6298-6309.

Lipton JO, Sahin M. 2014. The neurology of mTOR. Neuron 84: 275-291.

Liu JJ, Ding J, Wu C, Bhagavatula P, Cui B, Chu S, Mobley WC, Yang Y. 2007. Retrolinkin, a membrane protein, plays an important role in retrograde axonal transport. Proc Natl Acad Sci U S A 104: 2223-2228.

Lom B, Cogen J, Sanchez AL, Vu T, Cohen-Cory S. 2002. Local and target-derived brain-derived neurotrophic factor exert opposing effects on the dendritic arborization of retinal ganglion cells in vivo. J Neurosci 22:7639-7649.

Lonze BE, Ginty DD. 2002. Function and regulation of CREB family transcription factors in the nervous system. Neuron 35:605-623.

Luikart BW, Zhang W, Wayman GA, Kwon CH, Westbrook GL, Parada LF. 2008. Neurotrophin-dependent dendritic filopodial motility: A convergence on PI3K signaling. J Neurosci 28:7006-7012.

Lush ME, Ma L, Parada LF. 2005. TrkB signaling regulates the developmental maturation of the somatosensory cortex. Int J Dev Neurosci 23:523-536.

Marler KJ, Suetterlin P, Dopplapudi A, Rubikaite A, Adnan J, Maiorano NA, Lowe AS, Thompson ID, Pathania M, Bordey A, Fulga T, Van Vactor DL, Hindges R, Drescher U. 2014. BDNF promotes axon branching of retinal ganglion cells via miRNA-132 and p250GAP. J Neurosci 34:969-979.

Marshak S, Nikolakopoulou AM, Dirks R, Martens GJ, CohenCory S. 2007. Cell-autonomous TrkB signaling in presynaptic retinal ganglion cells mediates axon arbor growth and synapse matura- tion during the establishment of retinotectal synaptic connectivity. J Neurosci 27:2444-2456.

Mason JM, Morrison DJ, Basson MA, Licht JD. 2006. Sprouty proteins: Multifaceted negative-feedback regulators of receptor tyrosine kinase signaling. Trend Cell Biol 16:45-54.

Masuda M, Takeda S, Sone M, Ohki T, Mori H, Kamioka Y, Mochizuki N. 2006. Endophilin BAR domain drives membrane curvature by two newly identified structure-based mechanisms. EMBO J 25:2889-2897.

McCaffrey G, Welker J, Scott J, der Salm L, Grimes ML. 2009. High-resolution fractionation of signaling endosomes containing different receptors. Traffic 10:938-950.

Minichiello L. 2009. TrkB signalling pathways in LTP and learning. Nat Rev Neurosci 10:850-860.

Minichiello L, Calella AM, Medina DL, Bonhoeffer T, Klein R, Korte M. 2002. Mechanism of TrkB-mediated hippocampal longterm potentiation. Neuron 36:121-137.

Mitchell DJ, Blasier KR, Jeffery ED, Ross MW, Pullikuth AK, Suo D, Park J, Smiley WR, Lo KW, Shabanowitz J, Deppmann CD, Trinidad JC, Hunt DF, Catling AD, Pfister KK. 2012. Trk activation of the ERK1/2 kinase pathway stimulates intermediate chain phosphorylation and recruits cytoplasmic dynein to signaling endosomes for retrograde axonal transport. J Neurosci 32:15495-15510.

Miyamoto Y, Yamauchi J, Tanoue A, Wu C, Mobley WC. 2006. TrkB binds and tyrosine-phosphorylates Tiam1, leading to activation of Rac1 and induction of changes in cellular morphology. Proc Natl Academy of Sciences of the United States of America 103: 10444-10449.

Mochizuki N, Yamashita S, Kurokawa K, Ohba Y, Nagai T, Miyawaki A, Matsuda M. 2001. Spatio-temporal images of growthfactor-induced activation of Ras and Rap1. Nature 411:1065-1068.

Mori Y, Matsui T, Furutani Y, Yoshihara Y, Fukuda M. 2012. Small GTPase Rab17 regulates dendritic morphogenesis and postsynaptic development of hippocampal neurons. J Biol Chem 287:8963-8973.

Mori Y, Matsui T, Fukuda M. 2013. Rabex-5 protein regulates dendritic localization of small GTPase Rab17 and neurite morphogenesis in hippocampal neurons. J Biol Chem 288:9835-9847.

Mufson EJ, Kroin JS, Sendera TJ, Sobreviela T. 1999. Distribution and retrograde transport of trophic factors in the central nervous system: Functional implications for the treatment of neurodegenerative diseases. Prog Neurobiol 57:451-484.

Munoz-Llancao P, Henriquez DR, Wilson C, Bodaleo F, Boddeke EW, Lezoualc'h F, Schmidt M, Gonzalez-Billault C. 2015. Exchange protein directly activated by cAMP (EPAC) regulates neuronal polarization through Rap1B. J Neurosci 35:11315-11329.

Murakoshi H, Wang H, Yasuda R. 2011. Local, persistent activation of Rho GTPases during plasticity of single dendritic spines. Nature 472:100-104.

Myers JP, Robles E, Ducharme-Smith A, Gomez TM. 2012. Focal adhesion kinase modulates Cdc42 activity downstream of positive and negative axon guidance cues. J Cell Sci 125:2918-2929.

Namekata K, Harada C, Guo X, Kimura A, Kittaka D, Watanabe H, Harada T. 2012. Dock3 stimulates axonal outgrowth via GSK3beta-mediated microtubule assembly. J Neurosci 32:264-274.

Ohira K, Homma KJ, Hirai H, Nakamura S, Hayashi M. 2006. TrkB-T1 regulates the RhoA signaling and cytoskeleton in glioma cells. Biochem Biophys Res Commun 343:867-74.

Ouyang Q, Lizarraga SB, Schmidt M, Yang U, Gong J, Ellisor D, Kauer JA, Morrow EM. 2013. Christianson syndrome protein NHE6 modulates TrkB endosomal signaling required for neuronal circuit development. Neuron 80:97-112. 
Panagiotaki N, Dajas-Bailador F, Amaya E, Papalopulu N, Dorey K. 2010. Characterisation of a new regulator of BDNF signalling, Sprouty3, involved in axonal morphogenesis in vivo. Development 137:4005-4015.

Park H, Poo MM. 2013. Neurotrophin regulation of neural circuit development and function. Nat Rev Neurosci 14:7-23.

Philippidou P, Valdez G, Akmentin W, Bowers WJ, Federoff HJ, Halegoua S. 2011. Trk retrograde signaling requires persistent, Pincher-directed endosomes. Proc Natl Acad Sci U S A 108:852-857.

Rauskolb S, Zagrebelsky M, Dreznjak A, Deogracias R, Matsumoto T, Wiese S, Erne B, Sendtner M, Schaeren-Wiemers N, Korte M, Barde YA. 2010. Global deprivation of brain-derived neurotrophic factor in the CNS reveals an area-specific requirement for dendritic growth. J Neurosci 30:1739-1749.

Roland JT, DM, Bryant A, Datta A Itzen KE. Mostov JR, Goldenring 2011. Rab GTPase-Myo5B complexes control membrane recycling and epithelial polarization. Proc Natl Acad Sci U S A 108:2789-2794.

Roze E, Saudou F, Caboche J. 2008. Pathophysiology of Huntington's disease: From huntingtin functions to potential treatments. Curr Opin Neurol 21:497-503.

Ruiz CR, Shi J, Meffert MK. 2014. Transcript specificity in BDNFregulated protein synthesis. Neuropharmacology 76 Pt C:657-663.

Saito A, Miyajima K, Akatsuka J, Kondo H, Mashiko T, Kiuchi T, Ohashi K, Mizuno K. 2013. CaMKIIbeta-mediated LIM-kinase activation plays a crucial role in BDNF-induced neuritogenesis. Genes Cells 18:533-543.

Sancak Y, Peterson TR, Shaul YD, Lindquist RA, Thoreen CC, BarPeled L, Sabatini DM. 2008. The Rag GTPases bind raptor and mediate amino acid signaling to mTORC1. Science 320:1496-1501.

Sarmiere PD. JR, Bamburg 2004. Regulation of the neuronal actin cytoskeleton by ADF/cofilin. J Neurobiol 58:103-117.

Satoh D, Sato D, Tsuyama T, Saito M, Ohkura H, Rolls MM, Ishikawa F, Uemura T. 2008. Spatial control of branching within dendritic arbors by dynein-dependent transport of Rab5-endosomes. Nat Cell Biol 10:1164-1171.

Schmieg N, Menendez G, Schiavo G, Terenzio M. 2014. Signalling endosomes in axonal transport: Travel updates on the molecular highway. Semin Cell Dev Biol 27:32-43.

Schratt GM, Nigh EA, Chen WG, Hu L, Greenberg ME. 2004. BDNF regulates the translation of a select group of mRNAs by a mammalian target of rapamycin-phosphatidylinositol 3-kinasedependent pathway during neuronal development. J Neurosci 24: 7366-7377.

Schratt GM, Tuebing F, Nigh EA, Kane CG, Sabatini ME, Kiebler M, Greenberg ME. 2006. A brain-specific microRNA regulates dendritic spine development. Nature 439:283-289.

Schwartz PM, Borghesani PR, Levy RL, Pomeroy SL, Segal RA. 1997. Abnormal cerebellar development and foliation in BDNF-/mice reveals a role for neurotrophins in CNS patterning. Neuron 19: 269-281.

Shi SH, Jan LY, Jan YN. 2003. Hippocampal neuronal polarity specified by spatially localized $\mathrm{mPar} 3 / \mathrm{mPar} 6$ and PI 3-kinase activity. Cell 112:63-75.

Shimojo M, J, Courchet S, Pieraut N, Torabi-Rander R Sando 3rd F., Polleux A, Maximov 2015. SNAREs Controlling Vesicular Release of BDNF and Development of Callosal Axons. Cell Rep 11:1054-1066.

Song M, Giza J, Proenca CC, Jing D, Elliott M, Dincheva I, Shmelkov SV, Kim J, Schreiner R, Huang SH, Castren E, Prekeris R, Hempstead BL, Chao MV, Dictenberg JB, Rafii S, Chen ZY,
Rodriguez-Boulan E, Lee FS. 2015. Slitrk5 mediates BDNF-dependent TrkB receptor trafficking and signaling. Dev Cell 33:690-702.

Stenmark H. 2009. Rab GTPases as coordinators of vesicle traffic. Nat Rev Mol Cell Biol 10:513-525.

Sun Y, Lim Y, Li F, Liu S, Lu JJ, Haberberger R, Zhong JH, Zhou XF. 2012. ProBDNF collapses neurite outgrowth of primary neurons by activating RhoA. PloS One 7:e35883.

Suzuki S, Numakawa T, Shimazu K, Koshimizu H, Hara T, Hatanaka H, Mei L, Lu B, Kojima M. 2004. BDNF-induced recruitment of TrkB receptor into neuronal lipid rafts: Roles in synaptic modulation. J Cell Biol 167:1205-1215.

Takano T, Tomomura M, Yoshioka N, Tsutsumi K, Terasawa Y, Saito T, Kawano H, Kamiguchi H, Fukuda M, Hisanaga S. 2012. LMTK1/AATYK1 is a novel regulator of axonal outgrowth that acts via Rab11 in a Cdk5-dependent manner. J Neurosci 32:6587-6599.

Takei N, Inamura N, Kawamura M, Namba H, Hara K, Yonezawa K, Nawa H. 2004. Brain-derived neurotrophic factor induces mammalian target of rapamycin-dependent local activation of translation machinery and protein synthesis in neuronal dendrites. J Neurosci 24:9760-9769.

Takemoto-Kimura S, Ageta-Ishihara N, Nonaka M, AdachiMorishima A, Mano T, Okamura M, Fujii H, Fuse T, Hoshino M, Suzuki S, Kojima M, Mishina M, Okuno H, Bito H. 2007. Regulation of dendritogenesis via a lipid-raft-associated Ca2+/calmodulin-dependent protein kinase CLICK-III/CaMKIgamma. Neuron 54:755-770.

Troca-Marin JA, Alves-Sampaio A, Tejedor FJ, Montesinos ML. 2010. Local translation of dendritic RhoA revealed by an improved synaptoneurosome preparation. Mol Cell Neurosci 43:308-314.

Van Aelst L, Cline HT. 2004. Rho GTPases and activity-dependent dendrite development. Curr Opin Neurobiol 14:297-304.

Villarroel-Campos D, Gonzalez-Billault C. 2014. The MAP1B case: An old MAP that is new again. Dev Neurobiol 74:953-971.

Villarroel-Campos D, Gastaldi L, Conde C, Caceres A, GonzalezBillault C. 2014. Rab-mediated trafficking role in neurite formation. J Neurochem 129:240-248.

Wong ST, JR, Henley KC, Kanning KH Huang M. Bothwell MM, Poo 2002. A p75(NTR) and Nogo receptor complex mediates repulsive signaling by myelin-associated glycoprotein. Nat Neurosci 5:1302-1308.

Wood GE, Young LT, Reagan LP, Chen B, McEwen BS. 2004. Stress-induced structural remodeling in hippocampus: Prevention by lithium treatment. Proc Nat Acad Sci U S A 101:3973-3978.

Wu C, Lai CF, Mobley WC. 2001. Nerve growth factor activates persistent Rap1 signaling in endosomes. J Neurosci 21:5406-5416.

Wu SH, Arevalo JC, Sarti F, Tessarollo L, Gan WB, Chao MV. 2009. Ankyrin Repeat-rich Membrane Spanning/Kidins220 protein regulates dendritic branching and spine stability in vivo. Dev Neurobiol 69:547-557.

Xing J, Kornhauser JM, Xia Z, Thiele EA, Greenberg ME. 1998. Nerve growth factor activates extracellular signal-regulated kinase and p38 mitogen-activated protein kinase pathways to stimulate CREB serine 133 phosphorylation. Mol Cell Biol 18:1946-1955.

Xu B, Zang K, Ruff NL, Zhang YA, McConnell SK, Stryker MP, Reichardt LF. 2000. Cortical degeneration in the absence of neurotrophin signaling: Dendritic retraction and neuronal loss after removal of the receptor TrkB. Neuron 26:233-245.

Yacoubian TA, Lo DC. 2000. Truncated and full-length TrkB receptors regulate distinct modes of dendritic growth. Nat Neurosci 3:342-349.

Yamashita T, Tohyama M. 2003. The p75 receptor acts as a displacement factor that releases Rho from Rho-GDI. Nat Neurosci 6:461-467. 
Yamashita T, Tucker KL, Barde YA. 1999. Neurotrophin binding to the p75 receptor modulates Rho activity and axonal outgrowth. Neuron 24:585-593.

Yamashita T, Higuchi H, Tohyama M. 2002. The p75 receptor transduces the signal from myelin-associated glycoprotein to Rho. J Cell Biol 157:565-570.

Yamashita N, Ohshima T, Nakamura F, Kolattukudy P, Honnorat J, Mikoshiba K, Goshima Y. 2012. Phosphorylation of CRMP2 (collapsin response mediator protein 2) is involved in proper dendritic field organization. J Neurosci 32:1360-1365.

Yan Q, Radeke MJ, Matheson CR, Talvenheimo J, Welcher AA, Feinstein SC. 1997. Immunocytochemical localization of TrkB in the central nervous system of the adult rat. J Comp Neurol 378: 135-157.

Yang J, Harte-Hargrove LC, Siao CJ, Marinic T, Clarke R, Ma Q, Jing D, Lafrancois JJ, Bath KG, Mark W, Ballon D, Lee FS, Scharfman HE, Hempstead BL. 2014. proBDNF negatively regulates neuronal remodeling, synaptic transmission, and synaptic plasticity in hippocampus. Cell Rep 7:796-806.

Yano H, Lee FS, Kong H, Chuang J, Arevalo J, Perez P, Sung C, Chao MV. 2001. Association of Trk neurotrophin receptors with components of the cytoplasmic dynein motor. J Neurosci 21: RC125.

Ye H, Kuruvilla R, Zweifel LS, Ginty DD. 2003. Evidence in support of signaling endosome-based retrograde survival of sympathetic neurons. Neuron 39:57-68.

York RD, Yao H, Dillon T, Ellig CL, Eckert SP, McCleskey EW, Stork PJ. 1998. Rap1 mediates sustained MAP kinase activation induced by nerve growth factor. Nature 392:622-626.
Yoshimura T, Kawano Y, Arimura N, Kawabata S, Kikuchi A, Kaibuchi K. 2005. GSK-3beta regulates phosphorylation of CRMP2 and neuronal polarity. Cell 120:137-149.

Yuan XB, Jin $\mathrm{M}, \mathrm{Xu} \mathrm{X}$, Song YQ, Wu CP, Poo MM, Duan S. 2003. Signalling and crosstalk of Rho GTPases in mediating axon guidance. Nat Cell Biol 5:38-45.

Zagrebelsky M, Holz A, Dechant G, Barde YA, Bonhoeffer T, Korte M. 2005. The p75 neurotrophin receptor negatively modulates dendrite complexity and spine density in hippocampal neurons. J Neurosci 25:9989-9999.

Zhang Y, Moheban DB, Conway BR, Bhattacharyya A, Segal RA. 2000. Cell surface Trk receptors mediate NGF-induced survival while internalized receptors regulate NGF-induced differentiation. J Neurosci 20:5671-5678.

Zheng J, Shen WH, Lu TJ, Zhou Y, Chen Q, Wang Z, Xiang T, Zhu YC, Zhang C, Duan S, Xiong ZQ. 2008. Clathrin-dependent endocytosis is required for TrkB-dependent Akt-mediated neuronal protection and dendritic growth. J Biol Chem 283: $13280-13288$

Zhou B, Cai Q, Xie Y, Sheng ZH. 2012. Snapin recruits dynein to BDNF-TrkB signaling endosomes for retrograde axonal transport and is essential for dendrite growth of cortical neurons. Cell Rep 2:42-51.

Zou W, Yadav S, DeVault L, Nung Jan Y, Sherwood DR. 2015. RAB-10-dependent membrane transport is required for dendrite arborization. PLoS Genet 11:e1005484.

Zuccaro E, Bergami M, Vignoli B, Bony G, Pierchala BA, Santi S, Cancedda L, Canossa M. 2014. Polarized expression of p75(NTR) specifies axons during development and adult neurogenesis. Cell Rep 7:138-152. 